\title{
Comparing the effectiveness of small-particle versus large-particle inhaled corticosteroid in COPD
}

This article was published in the following Dove Press journal: International Journal of COPD

17 October 2014

Number of times this article has been viewed

\author{
Dirkje S Postma' \\ Nicolas Roche ${ }^{2}$ \\ Gene Colice $^{3}$ \\ Elliot Israel ${ }^{4}$ \\ Richard J Martin ${ }^{5}$ \\ Willem MC van Aalderen ${ }^{6}$ \\ Jonathan Grigg ${ }^{7}$ \\ Anne Burden ${ }^{8}$ \\ Elizabeth $\mathrm{V}$ Hillyer ${ }^{8}$ \\ Julie von Ziegenweidt ${ }^{8}$ \\ Gokul Gopalan` \\ David Price 8,10
}

'University of Groningen, Department of Pulmonary Medicine and Tuberculosis, University Medical Center Groningen, Groningen, the Netherlands; ${ }^{2}$ Respiratory and Intensive Care Medicine, Cochin Hospital Group, APHP, Paris-Descartes University (EA25II), Paris, France; ${ }^{3}$ Pulmonary, Critical Care and Respiratory Services, Washington Hospital Center and George Washington University School of Medicine, Washington DC, USA; ${ }^{4}$ Pulmonary and Critical Care Division, Brigham and Women's Hospital, Harvard Medical School, Boston, MA, USA; ${ }^{5}$ Department of Medicine, National Jewish Health, Denver, CO, USA; ${ }^{6}$ Dept of Pediatric Respiratory Medicine and Allergy, Emma Children's Hospital AMC, Amsterdam, the Netherlands; ${ }^{7}$ Blizard Institute, Queen Mary University London, London, UK; ${ }^{8}$ Research in Real Life, Ltd, Cambridge, UK; ' ${ }^{\text {Respiratory, Global }}$ Scientific Affairs, Teva Pharmaceuticals, Frazer, PA, USA; ${ }^{10}$ Academic Primary Care, Division of Applied Health Sciences, University of Aberdeen, Aberdeen, UK

Correspondence: David Price Academic Primary Care, Division of Applied Health Sciences, University of Aberdeen, Polwarth Building, Foresterhill, Aberdeen AB25 2ZD, UK

Tel +44 I 60387 I 500

Fax +448082800792

Email dprice@rirl.org
Purpose: Small airway changes and dysfunction contribute importantly to airway obstruction in chronic obstructive pulmonary disease (COPD), which is currently treated with inhaled corticosteroids (ICS) and long-acting bronchodilators at Global initiative for Obstructive Lung Disease (GOLD) grades 2-4. This retrospective matched cohort analysis compared effectiveness of a representative small-particle ICS (extrafine beclomethasone) and larger-particle ICS (fluticasone) in primary care patients with COPD.

Patients and methods: Smokers and ex-smokers with COPD $\geq 40$ years old initiating or stepping-up their dose of extrafine beclomethasone or fluticasone were matched 1:1 for demographic characteristics, index prescription year, concomitant therapies, and disease severity during 1 baseline year. During 2 subsequent years, we evaluated treatment change and COPD exacerbations, defined as emergency care/hospitalization for COPD, acute oral corticosteroids, or antibiotics for lower respiratory tract infection.

Results: Mean patient age was 67 years, $57 \%-60 \%$ being male. For both initiation ( $n=334: 334$ ) and step-up ( $n=189: 189)$ patients, exacerbation rates were comparable between extrafine beclomethasone and fluticasone cohorts during the 2 year outcome period. Odds of treatment stability (no exacerbation or treatment change) were significantly greater for patients initiating extrafine beclomethasone compared with fluticasone (adjusted odds ratio 2.50; $95 \%$ confidence interval, 1.32-4.73). Median ICS dose exposure during 2 outcome years was significantly lower $(P<0.001)$ for extrafine beclomethasone than fluticasone cohorts $(315 \mu \mathrm{g} /$ day versus $436 \mu \mathrm{g} /$ day for initiation, $438 \mu \mathrm{g} /$ day versus $534 \mu \mathrm{g}$ /day for step-up patients).

Conclusion: We observed that small-particle ICS at significantly lower doses had comparable effects on exacerbation rates as larger-particle ICS at higher doses, whereas initiation of small-particle ICS was associated with better odds of treatment stability during 2-years' follow-up.

Keywords: COPD exacerbation, extrafine particle, matched cohort analysis, real life, small airways

\section{Introduction}

Chronic obstructive pulmonary disease (COPD) is a heterogeneous disorder characterized by chronic inflammation in airway walls and lung tissue, dysfunctional repair and defense mechanisms, excessive mucus production, and changes in the small peripheral airways. ${ }^{1,2}$ These changes include thickening of small airway walls, loss of elasticity, airway obstruction, and accompanying emphysema. ${ }^{3-5}$ A recent study found that loss of functional small airways may precede the development of emphysema in COPD and thus the small airways may constitute an appropriate target for treatment. ${ }^{6,7}$ 
Consensus practice guidelines for COPD recommend the use of inhaled corticosteroids (ICS) together with inhaled long-acting bronchodilators for patients at high risk of exacerbations, ie, with either forced expiratory volume in 1 second $\left(\mathrm{FEV}_{1}\right)<50 \%$ predicted or a history of repeated exacerbations. ${ }^{1}$ In randomized controlled trials, ICS reduce COPD exacerbations but are associated with a slight increase in risk of pneumonia. ${ }^{1,8-10}$ In clinical practice, different from current guideline recommendations, ICS monotherapy, usually with larger-particle ICS, is still being used for treatment of COPD. ${ }^{11-13}$

Because COPD starts in the small airways, a pharmacological approach targeting the small airways with smallparticle ICS might be beneficial. It may, however, be difficult to capture benefits related to small particle size in randomized controlled trials, which usually recruit selected patients who are cared for in a controlled context. Possible benefits might be more evident in real-life patients, whose adherence is often suboptimal and who may have COPD associated with other diseases, for example, asthma-COPD overlap syndrome. ${ }^{1}$ The aim of this retrospective observational study was to compare the effectiveness of a representative small-particle ICS, extrafine beclomethasone, ${ }^{14-16}$ and a larger-particle-size ICS, fluticasone, in a broad, real-life primary care population of patients with COPD. Our hypothesis was that treatment with small-particle ICS would be associated with improved management and control of COPD, as compared with largerparticle ICS, because of better deposition throughout the lungs and small airways.

\section{Methods}

\section{Study design and patients}

We performed retrospective matched cohort analyses using de-identified patient information (1996-2010) from $>450$ primary care practices throughout the UK subscribing to the General Practice Research Database (now in the Clinical Practice Research Datalink) ${ }^{17}$ and approximately 300 practices subscribing to the Optimum Patient Care Research Database. ${ }^{18}$ These two large electronic datasets, described in detail elsewhere, ${ }^{17-21}$ are frequently used for observational research. Patient characteristics were crossreferenced between the two datasets to avoid duplication of individuals.

The two analyses examined patients prescribed their first ICS treatment (initiation sample) and those prescribed an increase in ICS dose (step-up sample) for COPD as either extrafine beclomethasone (Qvar; Teva Pharmaceuticals, Petach Tikva, Israel) or a commonly prescribed large-particle
ICS, fluticasone (Flixotide; GlaxoSmithKline plc, London, UK), by pressurized metered-dose inhaler. We included male and female patients, $\geq 40$ years old at the time of the index study prescription (index date), who had: 1) a diagnostic code for COPD, and 2) two or more prescriptions for COPD at different time points during the preceding year (baseline). The baseline year COPD prescriptions could be for any combination of the following: short-acting $\beta_{2}$-agonist (SABA), long-acting $\beta_{2}$-agonist (LABA), short-acting muscarinic antagonist (SAMA), long-acting muscarinic antagonist (LAMA), theophylline, and, for patients in the step-up sample only, including an ICS. The diagnostic code for COPD could be recorded at any time relative to the index date ICS prescription. Eligible patients had to be registered at the same general practice for at least 3 consecutive years, including 1 year before (baseline year) and 2 years after the index date (outcome period).

In practice COPD can be associated with or misdiagnosed as asthma; therefore, eligible patients could also have had an asthma diagnostic code but only if recorded for the first time after 40 years of age. Patients were excluded if they had a coded diagnosis pre-40-years for asthma or at any time for any chronic respiratory disease other than COPD (exclusions listed in Table S1). In addition, during the matching process (see below), we excluded non-smokers and patients without spirometric evidence of COPD (ie, without post-bronchodilator ratio of $\mathrm{FEV}_{1}$ to forced vital capacity $\left.[\mathrm{FVC}]\left[\mathrm{FEV}_{1} / \mathrm{FVC}\right]<0.7\right)$.

\section{Outcome measures}

Exacerbation rate and odds of COPD treatment success were the two coprimary effectiveness measures. An exacerbation was defined as the occurrence of any one of the following: acute use of oral corticosteroids; unscheduled hospital admission or emergency department (ED) attendance for COPD or respiratory-related event; lower respiratory tract infection treated with antibiotics; or prescription for antibiotics with a lower respiratory database code within a \pm 5 day window. The absence of an exacerbation during the outcome period defined COPD treatment success.

Secondary effectiveness measures included the time to first exacerbation and treatment stability, defined as no treatment change plus no exacerbation. Treatment change was defined as an increase in ICS dose (of $\geq 50 \%$ ) and/or additional therapy (new since baseline year). Other outcomes examined included the hospitalization rate for lower respiratory causes; mortality rate after the study; oral candidiasis (coded diagnosis or therapy, namely, oral antifungal prescriptions); and two definitions of pneumonia: 1) unconfirmed 
cases with coded pneumonia diagnosis, and 2) pneumonia confirmed by chest radiograph or hospitalization within 1 month of diagnosis code. All outcome measures were derived from GP-provided Read codes in the electronic databases.

All ICS doses were standardized to equivalency with extrafine beclomethasone doses for the analyses, using a 1:1 ratio for extrafine beclomethasone and all fluticasone propionate formulations, and for both the latter a 1:2 dose ratio relative to budesonide and larger-particle chlorofluorocarbonor hydrofluoroalkane-beclomethasone (Clenil Modulite; Chiesi Ltd, Cheadle, UK). The mean daily ICS dose exposure during baseline and outcome years was calculated as the dispensed amount divided by 365 (baseline year) or 730 (outcome period).

\section{Statistical analysis}

We conducted a matched cohort analysis because the exploratory analysis found baseline differences between treatment cohorts in both initiation and step-up samples. Unmatched patients prescribed extrafine beclomethasone tended to be slightly older and to have fewer baseline exacerbations than those in the fluticasone cohorts. Most importantly, the index date, which was later for extrafine beclomethasone cohorts, was a strongly confounding variable because of trends over time for earlier COPD diagnosis and treatment. Hospitalization and mortality rates were significantly lower, and changes in therapy significantly more likely, with later index dates.

Therefore, to eliminate these and minimize other baseline differences between treatment cohorts, we matched in 1:1 ratio on the following criteria: sex; age ( \pm 5 years); number of baseline year COPD exacerbations $(0,1, \geq 2)$; year of index prescription $( \pm 1$ year for the initiation sample and \pm 2 years for the step-up sample); and baseline therapy (categorized as a) SABA/SAMA/SABA + SAMA; b) $\mathrm{LABA} \pm \mathrm{SABA} \pm \mathrm{SAMA}$; ) $\mathrm{LAMA} \pm \mathrm{SABA} \pm \mathrm{SAMA}$; d) $\mathrm{LABA}+\mathrm{LAMA} \pm \mathrm{SABA} \pm \mathrm{SAMA}$, and e) other). In addition, for the step-up sample, we matched on mean daily ICS dose exposure during baseline (categorized as 0-250, 251-500, and $>500 \mu \mathrm{g} /$ day). Finally, we matched on smoking status; confirmation of COPD ever via post-bronchodilator $\mathrm{FEV}_{1} / \mathrm{FVC}$ ratio $<0.7$; and age at first asthma diagnosis ( $<40$ years old or $\geq 40$ years old/no asthma diagnosis) as a means of subsequently excluding - without losing matched groupings - all non-smokers, patients without confirmed COPD, and patients with asthma diagnosed before age 40 .

Summary statistics were produced for all baseline and outcome variables. For patients with available $\mathrm{FEV}_{1}$ values, the Global initiative for Obstructive Lung Disease (GOLD) grade of severity of airflow limitation was determined. ${ }^{22}$ We compared baseline characteristics and unadjusted outcome variables for matched cohorts using conditional logistic regression, categorizing heavily skewed data. The list of potential confounders considered for the adjusted analyses included those differing between treatment cohorts at baseline $(P<0.10)$ and variables predictive $(P<0.05)$ of each outcome variable in multivariate analyses (Table S2). Pearson and Spearman correlation coefficients were applied, together with clinical interpretation, to eliminate variables presenting collinearity issues in the regression modeling of outcomes.

We used a conditional Poisson regression model to calculate adjusted relative rates of exacerbations and of oral candidiasis. The adjusted odds of achieving COPD treatment success and treatment stability, and of having a treatment change, were compared between cohorts using conditional binary logistic regression models. A Cox proportional hazards model, adjusted for baseline confounders, was used to examine the time to first exacerbation and post-study mortality. (Patients had to be alive during the full 2 year outcome period to be eligible for the study). To account for multiple comparisons, we controlled for false discovery rate if more than one of the co-primary endpoints were significant.

The composite outcome measures and analyses were prespecified according to standard operating procedures of the research group. ${ }^{23}$ All analyses were carried out using IBM SPSS Statistics version 19 (IBM Corporation, Armonk, NY, USA), SAS version 9.2 (SAS Institute Inc., Cary, NC, USA), and Microsoft Excel 2007 (Microsoft Corporation, Redmond, WA, USA). We defined statistically significant results as $P<0.05$.

\section{Results}

Patient identification in the datasets and subsequent matching of 384 patients in each initiation cohort, and 189 patients in each step-up cohort, are depicted in Figures S1 and S2.

\section{Initiation sample}

At baseline, the clinical characteristics of patients in extrafine beclomethasone and fluticasone cohorts were similar (Tables 1 and S3). Approximately $60 \%$ of patients were male, and the mean age was 67 years. There were several significant differences between cohorts (eg, in index prescription date, cardiac disease diagnosis, and use of some drugs), but these differences were small and not clinically meaningful. Most patients were GOLD grade 2 or $3 .^{22}$ 
Table I Summary of key baseline patient characteristics by matched treatment cohorts and smoking status

\begin{tabular}{|c|c|c|c|c|c|c|}
\hline \multirow[t]{2}{*}{ Characteristic } & \multicolumn{3}{|c|}{ Initiation sample } & \multicolumn{3}{|l|}{ Step-up sample } \\
\hline & $\begin{array}{l}\text { Extrafine BDP } \\
(n=334)\end{array}$ & $\begin{array}{l}\text { Fluticasone } \\
(n=334)\end{array}$ & $P$-value ${ }^{a}$ & $\begin{array}{l}\text { Extrafine BDP } \\
(n=189)\end{array}$ & $\begin{array}{l}\text { Fluticasone } \\
(\mathrm{n}=189)\end{array}$ & $P$-value ${ }^{a}$ \\
\hline Male sex, $\mathrm{n}(\%)^{\mathrm{b}}$ & $201(60.2)$ & $201(60.2)$ & $\mathrm{n} / \mathrm{a}$ & $108(57.1)$ & $108(57.1)$ & $\mathrm{n} / \mathrm{a}$ \\
\hline Age at index date, mean (SD) ${ }^{\mathbf{b}}$ & $66.5(8.4)$ & $66.6(8.1)$ & 0.61 & $67.2(8.3)$ & $67.1(8.6)$ & 0.79 \\
\hline $\mathrm{BMI}$ in $\mathrm{kg} / \mathrm{m}^{2}$, mean $(\mathrm{SD})^{\mathrm{c}}$ & $26.4(5.5)$ & $26.1(4.7)$ & 0.46 & $26.5(5.2)$ & $26.6(5.5)$ & 0.66 \\
\hline \multicolumn{7}{|l|}{ Charlson comorbidity index score, n (\%) } \\
\hline 0 & $205(6 \mid .4)$ & $195(58.4)$ & 0.48 & $119(63.0)$ & $100(52.9)$ & 0.13 \\
\hline 1 & $70(21.0)$ & $67(20.1)$ & & $30(15.9)$ & $47(24.9)$ & \\
\hline 2 & $28(8.4)$ & $46(13.8)$ & & $26(13.8)$ & $21(11.1)$ & \\
\hline$\geq 3$ & $31(9.3)$ & $26(7.8)$ & & $14(7.4)$ & $21(11.1)$ & \\
\hline Current smoker, n (\%) & $165(49.7)$ & $162(48.8)$ & 0.81 & $75(39.9)$ & $78(41.5)$ & 0.74 \\
\hline Ex-smoker, n (\%) & $167(50.3)$ & $170(51.2)$ & & $113(60.1)$ & $110(58.5)$ & \\
\hline Index prescription date, mean (SD) & $2003.1(2.3)$ & $2002.8(2.3)$ & $<0.001$ & $2003.3(2.2)$ & $2002.7(2.2)$ & $<0.001$ \\
\hline \multicolumn{7}{|l|}{ Recorded comorbidity, n (\%) } \\
\hline Asthma diagnosis & $183(54.8)$ & I $87(56.0)$ & 0.74 & |4| (74.6) & I 45 (76.7) & 0.63 \\
\hline Rhinitis diagnosis & $38(11.4)$ & $48(14.4)$ & 0.25 & $28(14.8)$ & $31(16.4)$ & 0.63 \\
\hline GERD diagnosis & $49(14.7)$ & $54(16.2)$ & 0.58 & $26(13.8)$ & $30(15.9)$ & 0.56 \\
\hline Cardiac disease diagnosis & $70(21.0)$ & $45(13.5)$ & 0.010 & $45(23.8)$ & $34(18.0)$ & 0.15 \\
\hline \multicolumn{7}{|l|}{ Exacerbations, $\mathrm{n}(\%)^{\mathrm{b}}$} \\
\hline 0 (COPD treatment success) & $|3|(39.2)$ & I31 (39.2) & $\mathrm{n} / \mathrm{a}$ & $73(38.6)$ & $73(38.6)$ & $\mathrm{n} / \mathrm{a}$ \\
\hline I & $81(24.3)$ & $81(24.3)$ & & $33(17.5)$ & $33(17.5)$ & \\
\hline$\geq 2$ & $122(36.5)$ & $122(36.5)$ & & $83(43.9)$ & $83(43.9)$ & \\
\hline Patients with $\geq 4$ exacerbations & $39(11.7)$ & $28(8.4)$ & - & $29(15.3)$ & $26(13.8)$ & \\
\hline Recorded \%predicted FEV, n (\%) & $300(89.8)$ & $280(83.8)$ & - & $169(89.4)$ & $163(86.2)$ & - \\
\hline \%predicted $\mathrm{FEV}_{1}$, mean (SD) & $52.9(17.9)$ & $52.5(18.7)$ & 0.90 & $55.3(19.3)$ & $52.4(17.9)$ & 0.21 \\
\hline \%predicted $\mathrm{FEV},<60 \%, \mathrm{n}(\%)$ & $202(67.3)$ & $193(68.9)$ & - & I0I (59.8) & $108(66.3)$ & - \\
\hline \multicolumn{7}{|l|}{ GOLD grade ${ }^{22, c}, \mathrm{n}(\%)$} \\
\hline GOLD I & $15(5.4)$ & $19(7.2)$ & 0.75 & $12(7.9)$ & $7(4.5)$ & 0.12 \\
\hline GOLD 2 & $126(45.5)$ & $109(4 \mid .3)$ & & $73(48.0)$ & $74(47.7)$ & \\
\hline GOLD 3 & $106(38.3)$ & $104(39.4)$ & & $51(33.6)$ & $51(32.9)$ & \\
\hline GOLD 4 & $30(10.8)$ & $32(12.1)$ & & $16(10.5)$ & $23(14.8)$ & \\
\hline \multicolumn{7}{|l|}{ Baseline therapy, $\mathrm{n}(\%)^{\mathrm{b}}$} \\
\hline SABA & I54 (46.I) & $128(38.3)$ & 0.027 & $88(46.6)$ & $77(40.7)$ & 0.057 \\
\hline SAMA & $22(6.6)$ & $26(7.8)$ & & II (5.8) & $5(2.6)$ & \\
\hline$S A M A+S A B A$ & II 4 (34.I) & $136(40.7)$ & & $35(18.5)$ & $52(27.5)$ & \\
\hline $\mathrm{LABA} \pm \mathrm{SAMA} \pm \mathrm{SABA}$ & $33(9.9)$ & $33(9.9)$ & & $51(27.0)$ & $5 I(27.0)$ & \\
\hline $\mathrm{LAMA} \pm \mathrm{SAMA} \pm \mathrm{SABA}$ & $7(2.1)$ & $7(2.1)$ & & $2(1.1)$ & $2(1.1)$ & \\
\hline $\mathrm{LAMA}+\mathrm{LABA} \pm \mathrm{SAMA} \pm \mathrm{SABA}$ & $\mathrm{I}(0.3)$ & $\mathrm{I}(0.3)$ & & $2(1.1)$ & $2(1.1)$ & \\
\hline Other & $3(0.9)$ & $3(0.9)$ & & 0 & 0 & \\
\hline LABA during baseline year, $\mathrm{n}(\%)$ & $37(11.1)$ & $35(10.5)$ & 0.47 & $53(28.0)$ & $53(28.0)$ & $\mathrm{n} / \mathrm{a}$ \\
\hline COPD prescriptions, median (IQR) & $6(3-10)$ & $6(3-11)$ & 0.60 & $9(5-13)$ & $10(6-14)$ & 0.16 \\
\hline \multicolumn{7}{|l|}{ Mean daily ICS dose, $n(\%)^{b, d}$} \\
\hline $\mathrm{I}-50 \mu \mathrm{g} / \mathrm{d}$ & - & - & $\mathrm{n} / \mathrm{a}$ & $20(10.6)$ & II (5.8) & 0.13 \\
\hline $5 \mathrm{I}-100 \mu \mathrm{g} / \mathrm{d}$ & - & - & & $47(24.9)$ & $46(24.3)$ & \\
\hline $\mathrm{I} 0 \mathrm{I}-200 \mu \mathrm{g} / \mathrm{d}$ & - & - & & $51(27.0)$ & $60(31.7)$ & \\
\hline $20 \mathrm{I}-400 \mu \mathrm{g} / \mathrm{d}$ & & & & $51(27.0)$ & $49(25.9)$ & \\
\hline$>400 \mu \mathrm{g} / \mathrm{d}$ & - & - & & $20(10.6)$ & $23(12.2)$ & \\
\hline Oral candidiasis, ${ }^{e}$ diagnosis/Rx, n (\%) & $10(3.0)$ & II (3.3) & 0.82 & $10(5.3)$ & $5(2.6)$ & 0.15 \\
\hline $\begin{array}{l}\geq \mathrm{I} \text { inpatient admission for COPD/lower } \\
\text { respiratory condition, } \mathrm{n}(\%)\end{array}$ & $4(1.2)$ & $6(1.8)$ & 0.53 & $\mathrm{I}(0.5)$ & $\mathrm{I}(0.5)$ & 1.0 \\
\hline \multicolumn{7}{|l|}{ Antibiotic prescriptions for LRTI, $n(\%)$} \\
\hline 0 prescription & $218(65.3)$ & $216(64.7)$ & 0.39 & $123(65.1)$ & $|2|(64.0)$ & \\
\hline I prescription & $64(19.2)$ & $80(24.0)$ & & $37(19.6)$ & $36(19.0)$ & 0.67 \\
\hline
\end{tabular}


Table I (Continued)

\begin{tabular}{|c|c|c|c|c|c|c|}
\hline \multirow[t]{2}{*}{ Characteristic } & \multicolumn{3}{|c|}{ Initiation sample } & \multicolumn{3}{|l|}{ Step-up sample } \\
\hline & $\begin{array}{l}\text { Extrafine BDP } \\
(n=334)\end{array}$ & $\begin{array}{l}\text { Fluticasone } \\
(n=334)\end{array}$ & $P$-value ${ }^{a}$ & $\begin{array}{l}\text { Extrafine BDP } \\
(n=\mid 89)\end{array}$ & $\begin{array}{l}\text { Fluticasone } \\
(n=\mid 89)\end{array}$ & $P$-value ${ }^{a}$ \\
\hline$\geq 2$ prescriptions & $52(15.6)$ & $38(11.4)$ & & $29(15.3)$ & $32(16.9)$ & \\
\hline All patients with $\geq 4$ prescriptions & $13(3.9)$ & $5(1.5)$ & - & $3(1.6)$ & $10(5.3)$ & - \\
\hline
\end{tabular}

Notes: aMatched cohorts were compared using conditional logistic regression; ${ }^{\mathrm{b}}$ matching variable (age matching was \pm 5 years and index prescription date $\pm \mathrm{I}$ year for the initiation sample and \pm 2 years for the step-up sample); crecorded BMI data were available for 331 ( $99 \%$ ) and 328 ( $98 \%$ ) patients in extrafine beclomethasone and fluticasone initiation cohorts, respectively, and for 185 (98\%) and I84 (97\%) patients in extrafine beclomethasone and fluticasone step-up cohorts, respectively. Recorded GOLD severity data were available for 277 (83\%) and 264 (79\%) patients in extrafine beclomethasone and fluticasone initiation cohorts, respectively, and for I52 (80\%) and I55 (82\%) patients in extrafine beclomethasone and fluticasone step-up cohorts, respectively; 'the doses of ICS were standardized to equivalence with extrafine beclomethasone and fluticasone; thus, baseline doses of large-particle beclomethasone and budesonide were halved. The daily dose was calculated as the number of days' supply divided by number of prescription days; 'oral candidiasis was identified through coded diagnosis or therapy for same, namely, oral antifungal prescriptions.

Abbreviations: BDP, beclomethasone dipropionate; BMI, body mass index; COPD, chronic obstructive pulmonary disease; diagnosis/Rx, coded diagnosis or therapy for same; FEV, forced expiratory volume in I second; GERD, gastroesophageal reflux disease; GOLD, Global initiative for chronic Obstructive Lung Disease; ICS, inhaled corticosteroid; IQR, interquartile range; n/a, not applicable; LABA, long-acting $\beta_{2}$-agonist; LAMA, long-acting muscarinic antagonist; LRTI, lower respiratory tract infection; $\mathrm{Rx}$, therapy; SABA, short-acting $\beta_{2}$-agonist; SAMA, short-acting muscarinic antagonist; SD, standard deviation.

Prescribed index date doses of extrafine beclomethasone were significantly lower than those of fluticasone (median interquartile range [IQR], $200[200-400]$ versus $500[500$ $1,000] \mu \mathrm{g} / \mathrm{d} ; P<0.001$; Figure 1).

There were no significant differences between cohorts in the unadjusted or adjusted coprimary outcome measures (Table 2). Exacerbation rates fell during the 2 year outcome period relative to baseline in both cohorts (Figure 2 and Table 3); one third of patients in each cohort experienced COPD treatment success (no COPD exacerbation during the 2 outcome years).

The adjusted odds of treatment stability (no exacerbation or treatment change) were significantly better for extrafine beclomethasone (adjusted odds ratio [OR], 2.50; 95\% confidence interval [CI], 1.32-4.73), mainly driven by significantly lower odds of treatment change in that cohort (Table 2). Treatment changes during the outcome period are depicted in Figure 3. An increase in ICS dose by $\geq 50 \%$ was significantly more frequent in the extrafine beclomethasone cohort, while additional therapy was significantly more frequent in the fluticasone cohort (Table 2). The mean daily ICS dose exposure during outcome was significantly lower in the extrafine beclomethasone cohort (Table 2 and Figure 4).

A higher percentage of patients in the extrafine beclomethasone cohort had two or more lower respiratory tract infections requiring antibiotic therapy $(P=0.020)$, while hospitalizations for COPD and lower respiratory conditions were infrequent in both cohorts (Table 2). A total of seven $(2.1 \%)$ and four $(1.2 \%)$ patients in extrafine beclomethasone and fluticasone cohorts had a recorded diagnosis of pneumonia $(P=0.37)$; we considered the diagnosis confirmed for three $(0.9 \%)$ patients in each cohort. There was no difference between cohorts in the adjusted odds of developing oral candidiasis, experienced by roughly one in ten patients (Table 2).

\section{Step-up sample}

The extrafine beclomethasone and fluticasone cohorts were similar at baseline, with mean age of 67 years and 57\% male (Tables 1 and S3). A significant difference between cohorts in index date was small and not clinically meaningful (2003.3 versus 2002.7; $P<0.001$ ).

The stepped-up ICS dose prescribed at the index date was significantly lower for extrafine beclomethasone than fluticasone (median [IQR] 400 [400-400] versus 1,000 $[500-1,000] \mu \mathrm{g} / \mathrm{d} ; P<0.001$; Figure 1).

Unadjusted and adjusted results for effectiveness measures were comparable for the two step-up cohorts during the 2 year outcome period (Tables 3 and 4). As for the initiation sample, fewer patients in both cohorts experienced $\geq 2$ exacerbations/year relative to baseline (Figure 2). Adjusted odds of treatment stability and treatment change were similar in the two cohorts (Table 4 and Figure 3). Mean daily ICS dose exposure was significantly lower for extrafine beclomethasone (Table 4 and Figure 4).

The percentages of patients with lower respiratory tract infection requiring antibiotic therapy were similar in the two cohorts (Table 4); pneumonia was confirmed for two (1.1\%) patients in each cohort.

\section{Additional analyses}

Baseline patient characteristics were broadly similar for the matched and full unmatched patient cohorts (Table S4), and the unmatched results supported those for the matched cohorts (see Supplementary material). In post hoc sensitivity analyses, relative ICS doses and exacerbation rates among 

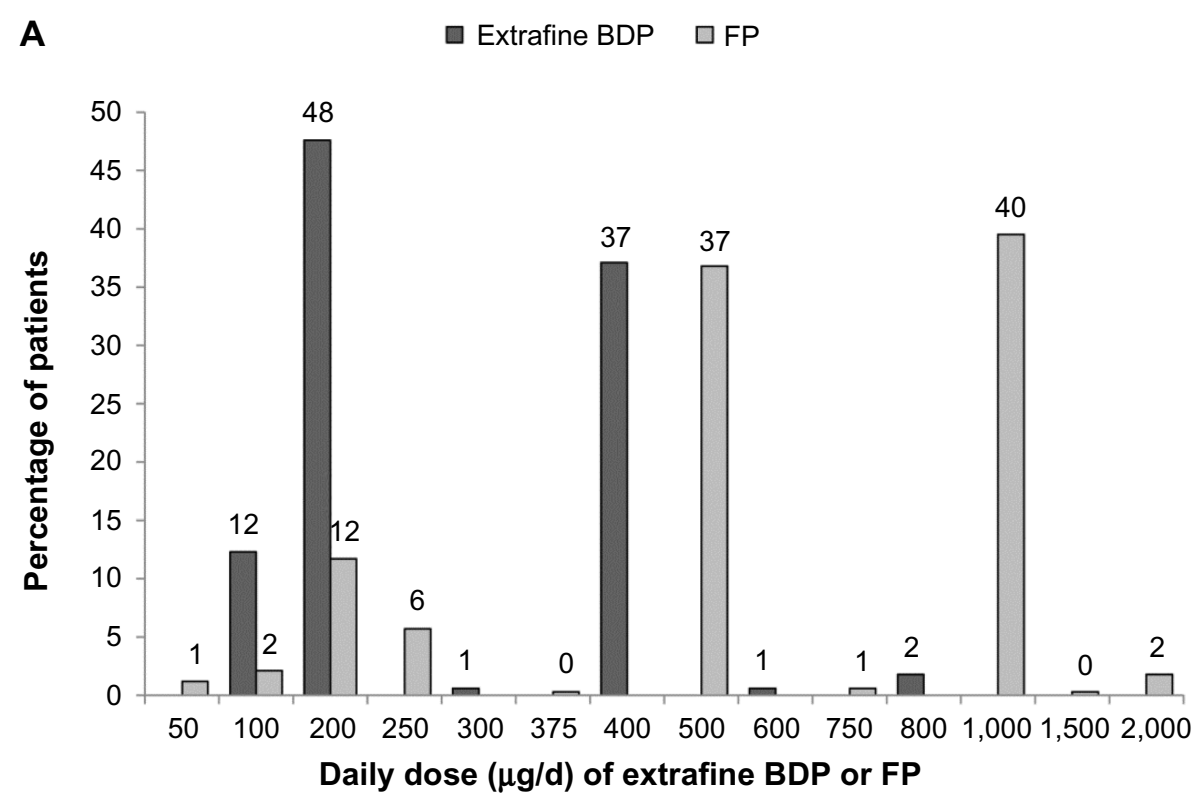

B $\quad$ Extrafine BDP $\quad$ 口FP

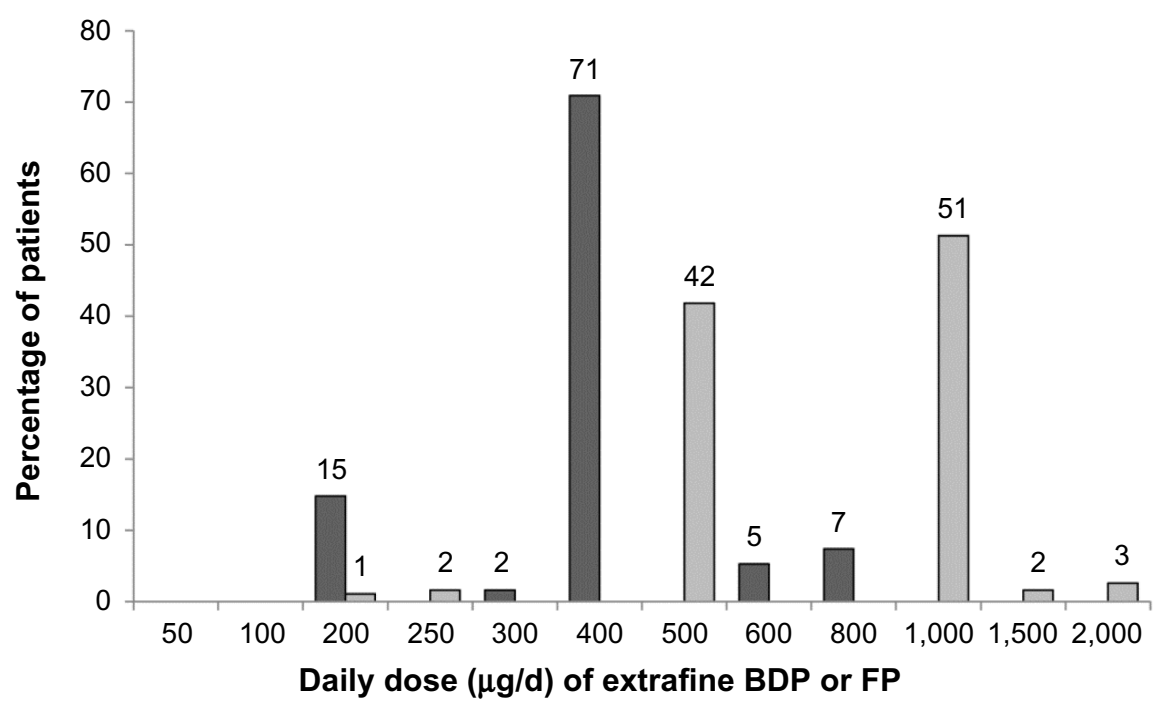

Figure I Daily dose of extrafine beclomethasone and larger-particle fluticasone as prescribed on the index date for (A) the initiation sample and (B) the step-up sample. Notes: $P<0.00$ I for the differences between cohorts. Percentages may not add up to $100 \%$ because of rounding; $x$-axis not to scale.

Abbreviations: BDP, beclomethasone dipropionate; FP, fluticasone propionate.

unmatched patients without a treatment change during the outcome period were similar to findings in the main analyses (Tables S5 and S6).

There was no significant difference between the two treatment cohorts of initiation or step-up samples in all-cause mortality after the outcome period (Table S7).

\section{Discussion}

We observed that COPD exacerbation rates in both initiation and step-up samples during the 2 year outcome period were comparable between matched cohorts prescribed extrafine beclomethasone or larger-particle fluticasone in this retrospective analysis. For patients initiating ICS for COPD, those prescribed extrafine beclomethasone had over twice the odds of treatment stability (no COPD exacerbation or treatment change) and half the odds of a treatment change. Index date prescribed doses of extrafine beclomethasone were significantly lower than doses of fluticasone, and the ICS dose exposure during the outcome period was significantly lower for both the initiation and step-up extrafine beclomethasone cohorts. 
Table 2 Unadjusted and adjusted results during the 2 year outcome period for the matched cohorts of the initiation sample

\begin{tabular}{|c|c|c|c|c|}
\hline Outcome & $\begin{array}{l}\text { Extrafine BDP } \\
(n=334)\end{array}$ & $\begin{array}{l}\text { Fluticasone } \\
(n=334)\end{array}$ & $\begin{array}{l}\text { Unadjusted odds, } \\
\text { hazard, or rate } \\
\text { ratio for extrafine } \\
\text { BDP }(95 \% \mathrm{Cl})\end{array}$ & $\begin{array}{l}\text { Adjusted odds, } \\
\text { hazard, or rate } \\
\text { ratio for extrafine } \\
\text { BDP }(95 \% \mathrm{Cl})\end{array}$ \\
\hline \multicolumn{5}{|l|}{ Coprimary outcome measures } \\
\hline COPD treatment success ( 0 exacerbations) & $118(35.3)$ & $119(35.6)$ & OR $0.98(0.70-1.39)$ & aOR I.0I $(0.70-1.46)^{\mathrm{b}}$ \\
\hline Exacerbations over 2 years & & & RR I.05 $(0.86-1.30)$ & aRR I.07 $(0.87-1.33)^{c}$ \\
\hline 0 & $118(35.3)$ & $119(35.6)$ & - & - \\
\hline I & $70(21.0)$ & $72(21.6)$ & - & - \\
\hline $2-3$ & $66(19.8)$ & $83(24.9)$ & - & - \\
\hline $4-6$ & $49(14.7)$ & $30(9.0)$ & - & - \\
\hline$\geq 7$ & $31(9.3)$ & $30(9.0)$ & - & - \\
\hline \multicolumn{5}{|l|}{ Secondary outcome measures } \\
\hline Time to first exacerbation, median $(95 \% \mathrm{Cl})$, days & $419(315-523)$ & $413(306-520)$ & HR I.07 (0.84-1.35) & aHR I.02 $(0.79-1.32)^{\mathrm{d}}$ \\
\hline Treatment stability (no Rx change or additional Rx) & $66(19.8)$ & $52(15.6)$ & OR I.40 $(0.91-2.16)$ & aOR $2.50(1.32-4.73)^{\mathrm{e}}$ \\
\hline Treatment change & $183(54.8)$ & $209(62.6)$ & OR $0.7 \mathrm{I}(0.5 \mathrm{I}-0.98)$ & aOR $0.49(0.32-0.75)^{f}$ \\
\hline \multirow[t]{2}{*}{ Oral candidiasis, diagnosis/Rx } & $28(8.4)$ & $36(10.8)$ & RR I.04 (0.53-2.0I) & aRR I.06 $(0.59-1.90)^{g}$ \\
\hline & & & $P$-value ${ }^{a}$ & \\
\hline \multicolumn{5}{|l|}{ Disaggregated outcome measures } \\
\hline I oral corticosteroid course & $58(17.4)$ & $51(15.3)$ & 0.44 & - \\
\hline$\geq 2$ oral corticosteroid courses & $56(16.8)$ & $52(15.6)$ & & \\
\hline I lower respiratory infection + antibiotic $\mathrm{Rx}$ & $69(20.7)$ & $72(21.6)$ & 0.020 & - \\
\hline$\geq 2$ lower respiratory infections + antibiotic $R x$ & $89(26.6)$ & $63(18.9)$ & & \\
\hline$\geq I$ hospitalization for COPD or lower respiratory & $12(3.6)$ & $9(2.7)$ & 0.49 & - \\
\hline Daily ICS dose ( $\mu \mathrm{g} / \mathrm{d})$, median (IQR) & $315(151-459)$ & $436(206-740)$ & $<0.001$ & - \\
\hline Daily SABA dose $(\mu \mathrm{g} / \mathrm{d})$, median (IQR) & $822(384-1,534)$ & $918(384-1,534)$ & 0.22 & - \\
\hline Increase in ICS dose by $\geq 50 \%$ & $96(28.7)$ & $68(20.4)$ & 0.017 & - \\
\hline Additional new therapy & $157(47.0)$ & $194(58.1)$ & 0.002 & - \\
\hline
\end{tabular}

Notes: Data are $\mathrm{n}(\%)$ unless otherwise indicated. Treatment change was defined as the first change and could include an increase in ICS dose and/or additional therapy. Additional new therapy was new for those patients and could be at any time during the 2 outcome years; patients could have received $\geq I$ additional therapy. ${ }^{a}$ Conditional logistic regression. Adjusted for baseline: btheophylline prescriptions and GERD diagnosis and/or therapy; 'antibiotics use, LABA, number of primary care consultations, and year of first coded diagnosis at practice; ${ }^{d}$ rhinitis diagnosis, amitriptyline, antibiotics use, number of COPD prescriptions, and time from first coded diagnosis at practice to index date; ${ }^{\mathrm{e}}$ year of index date; ' $y e a r$ of index date and time from first coded diagnosis at practice to index date; ${ }^{\mathrm{B}} \mathrm{cardiac}$ disease diagnosis, GERD diagnosis and/or therapy, number of COPD prescriptions, and oral candidiasis.

Abbreviations: aHR, adjusted hazard ratio; aOR, adjusted odds ratio; aRR, adjusted rate ratio; $\mathrm{BDP}$, beclomethasone dipropionate; $\mathrm{Cl}$, confidence interval; $\mathrm{COPD}$, chronic obstructive pulmonary disease; diagnosis/Rx, coded diagnosis or therapy for same; ICS, inhaled corticosteroid; IQR, interquartile range; Rx, treatment; SABA, short-acting $\beta_{2}$-agonist; OR, odds ratio; HR, hazard ratio; RR, rate ratio; GERD, gastroesophageal reflux disease; LABA, long-acting $\beta 2$-agonist.

The percentages of patients in each cohort who experienced $\geq 2$ exacerbations/year fell substantially during the outcome period. Relative to the baseline year, $11 \%-13 \%$ fewer patients in each initiation cohort, and $9 \%-16 \%$ fewer in each step-up cohort, experienced $\geq 2$ exacerbations/year. This finding suggests that pharmacotherapy was effective, as the experience of frequent COPD exacerbations ( $\geq 2 /$ year) is reportedly a relatively stable patient phenotype. ${ }^{24}$ These findings suggest, moreover, that increasing the dose of ICS can improve outcomes for some patients. Nonetheless, $25 \%-28 \%$ of patients in the extrafine beclomethasone cohorts and $18 \%-31 \%$ in fluticasone cohorts experienced $\geq 4$ exacerbations during the 2 year outcome period.

Although ICS are not recommended in COPD other than in fixed-dose combination with LABA, several studies have demonstrated some efficacy of ICS with regard to clinical outcomes ${ }^{25}$ and practice surveys in developed countries indicate that prescribing of ICS outside of fixed-dose combinations is not infrequent in usual care. ${ }^{11-13}$ (Moreover, fluticasone is licensed in some countries, including the Netherlands, for COPD). In this study, from $40 \%-49 \%$ of patients in initiation cohorts and from $33 \%-35 \%$ in step-up cohorts remained on ICS monotherapy at the end of the 2 year outcome period, not an ideal situation according to guideline recommendations but a reality of clinical practice and perhaps a reflection of earlier COPD treatment guidelines.

There is little other published work comparing ICS with different particle sizes for COPD. Two studies have compared combination ICS/LABA products. ${ }^{26,27}$ In a 12 week double-blind study of 18 patients with lung hyperinflation, the combination of extrafine beclomethasone/formoterol, but not larger-particle-size fluticasone/salmeterol, was effective in reducing air trapping and dyspnea. ${ }^{26}$ This concurs with our findings that the cohort initiating extrafine-particle ICS was 
A

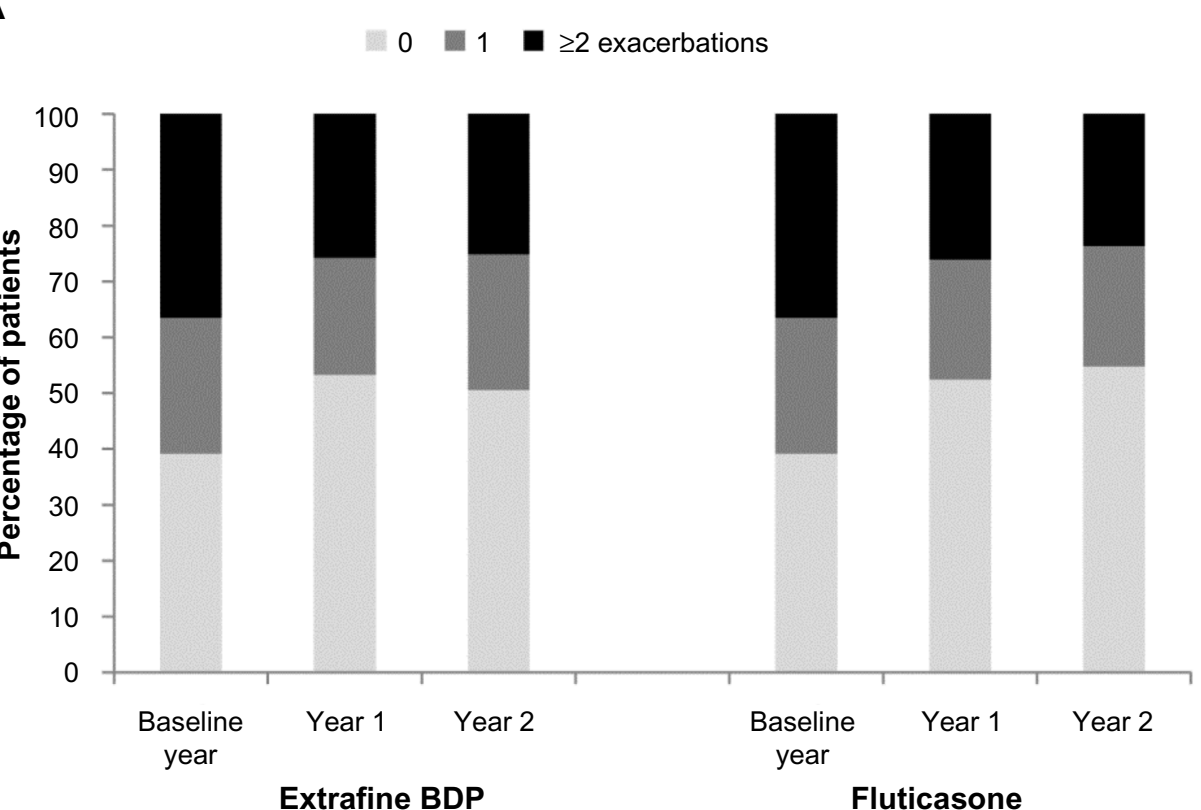

B

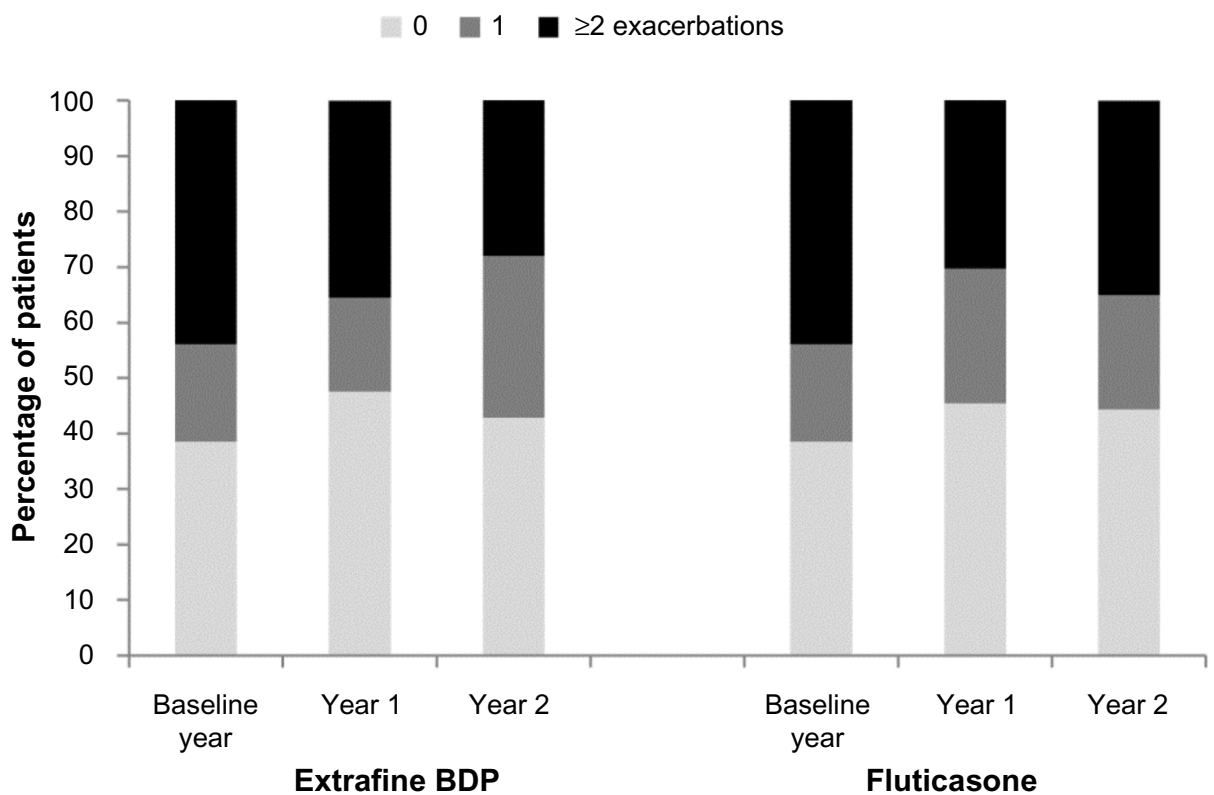

Figure 2 Percentage of patients experiencing 0 , I, or $\geq 2$ COPD exacerbations during the baseline year and years I and 2 of the 2 year outcome period in (A) the initiation sample and (B) the step-up sample.

Abbreviations: COPD, chronic obstructive pulmonary disease; BDP, beclomethasone dipropionate.

less frequently prescribed a treatment change than the cohort initiating larger-particle-size ICS. In another study, clinical outcomes for 232 patients prescribed beclomethasone/formoterol were similar to those for 238 patients prescribed larger-particle budesonide/formoterol with regard to COPD questionnaires and overall low exacerbation rates, while FVC improved more in those prescribed beclomethasone/ formoterol. ${ }^{27}$ The FVC results observed, and those of the prior study, ${ }^{26}$ could perhaps be explained by better distribution of extrafine particles to the small peripheral airways, an important site of inflammation in COPD. ${ }^{4,15,16}$

Further investigations and mechanistic studies are needed to explore the comparative effects of differing ICS particle sizes for treating COPD, including prospective pragmatic 
Table 3 Exacerbation rates during baseline and outcome periods

\begin{tabular}{|c|c|c|c|c|c|c|}
\hline \multirow[t]{2}{*}{ Exacerbations } & \multicolumn{3}{|c|}{ Initiation sample } & \multicolumn{3}{|l|}{ Step-up sample } \\
\hline & $\begin{array}{l}\text { Extrafine BDP } \\
(n=334)\end{array}$ & $\begin{array}{l}\text { Fluticasone } \\
(n=334)\end{array}$ & $P$-value ${ }^{a}$ & $\begin{array}{l}\text { Extrafine BDP } \\
(n=189)\end{array}$ & $\begin{array}{l}\text { Fluticasone } \\
(n=189)\end{array}$ & $P$-value ${ }^{a}$ \\
\hline Baseline year, mean (SD) & $1.4(1.8)$ & $\mathrm{I} .4(\mathrm{I} .8)$ & 0.47 & $\mathrm{I} .7(2.0)$ & $1.7(2.0)$ & 1.0 \\
\hline Median (IQR) & I $(0-2)$ & I (0-2) & & I (0-2) & I (0-2) & \\
\hline Outcome year I, mean (SD) & I.I8 (I.89) & $\mathrm{I} .07(\mathrm{l} .73)$ & 0.43 & $\mathrm{I} .46(2.0 \mathrm{I})$ & $1.31(1.92)$ & 0.47 \\
\hline Median (IQR) & $0(0-2)$ & $0(0-2)$ & & I (0-2) & I (0-2) & \\
\hline Outcome year 2, mean (SD) & $1.14(1.90)$ & $1.13(2.01)$ & 0.95 & $1.32(1.91)$ & I.5। (2.09) & 0.33 \\
\hline Median (IQR) & $0(0-2)$ & $0(0-1)$ & & I (0-2) & I (0-2) & \\
\hline
\end{tabular}

Note: a Matched cohorts were compared using conditional logistic regression.

Abbreviations: BDP, beclomethasone dipropionate; IQR, interquartile range; SD, standard deviation.

A

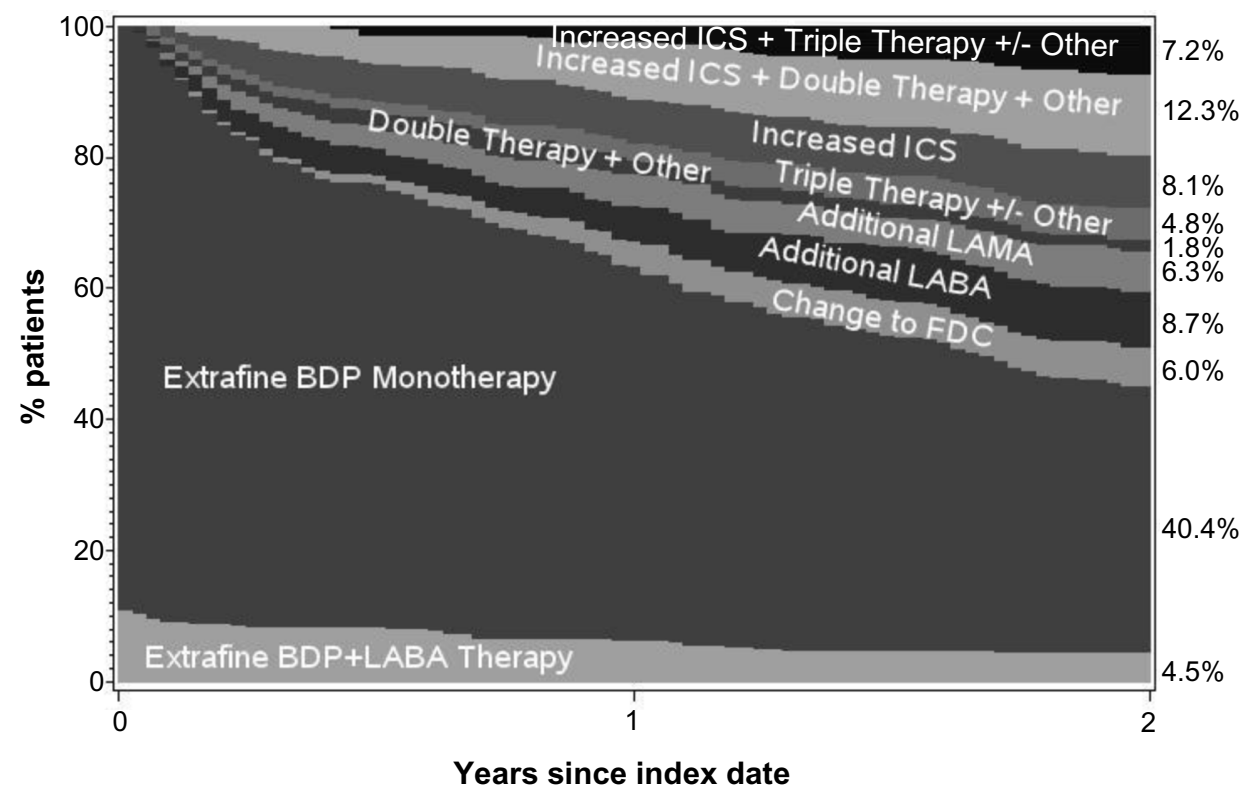

B

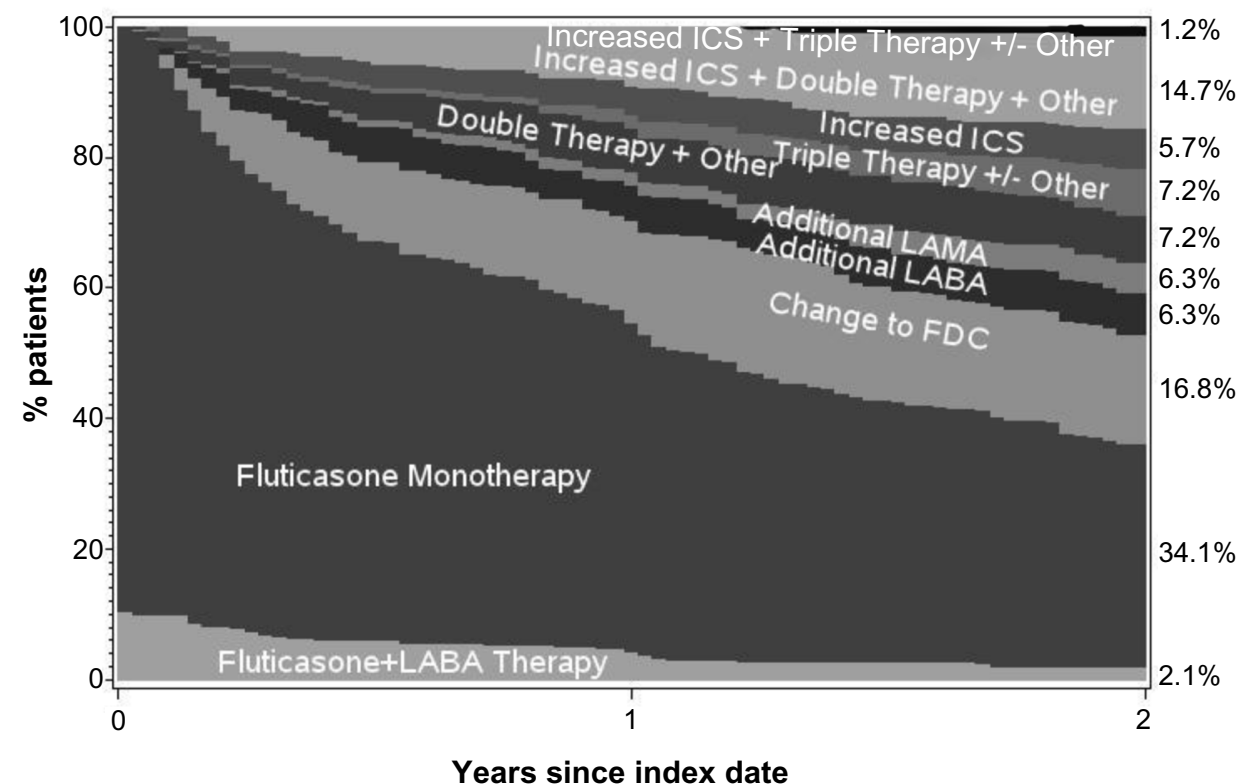

Figure 3 (Continued) 


\section{C}

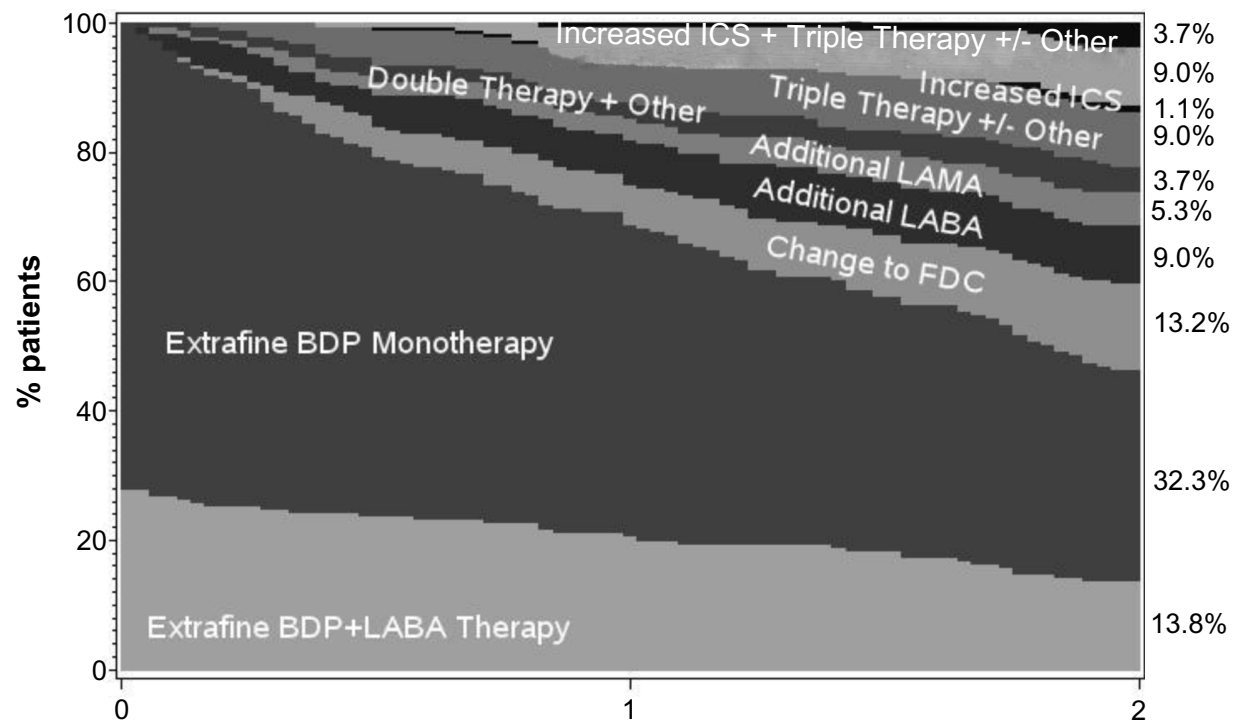

Years since index date

D

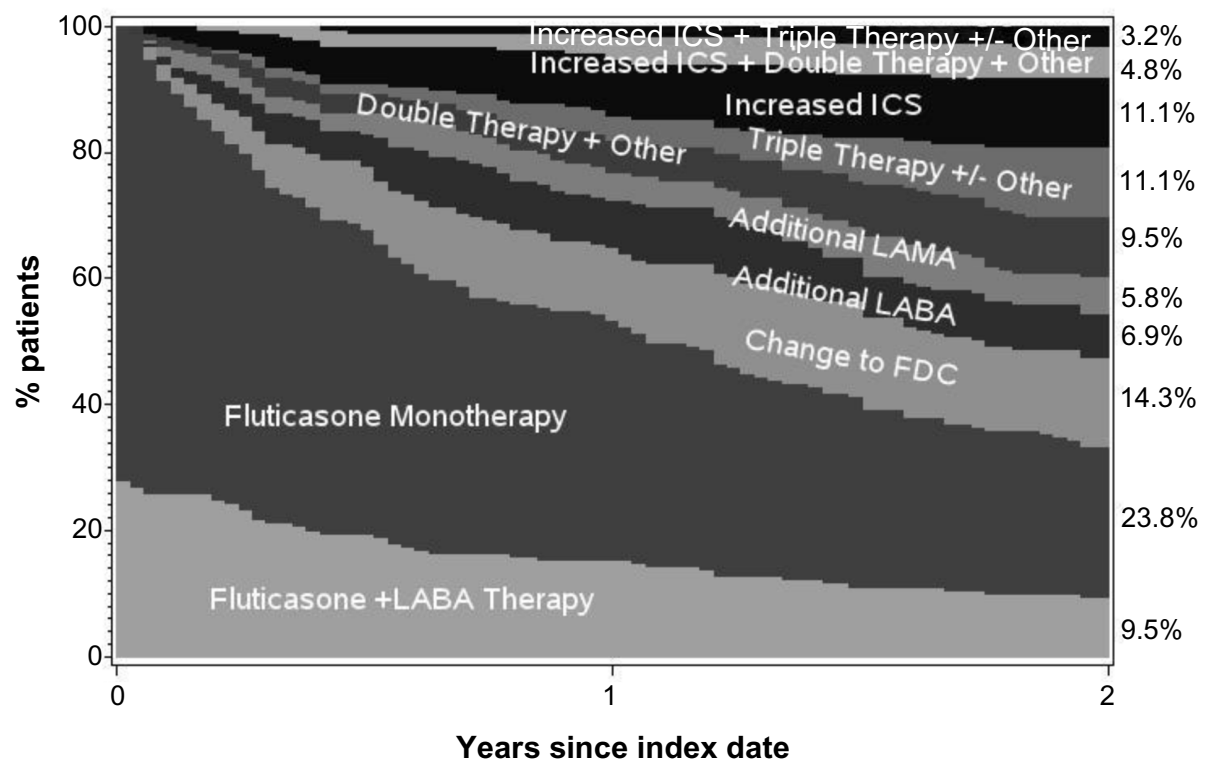

Figure 3 Changes in treatment and ICS dose during the 2 year outcome period for the (A) extrafine beclomethasone initiation cohort, (B) fluticasone initiation cohort, (C) extrafine beclomethasone step-up cohort, (D) fluticasone step-up cohort.

Note: "Other" includes LTRA and theophylline.

Abbreviations: BDP, beclomethasone dipropionate; FDC, fixed-dose combination ICS-LABA; ICS, inhaled corticosteroid; LABA, long-acting $\beta_{2}$-agonist; LAMA, long-acting muscarinic antagonist; LTRA, leukotriene receptor antagonist.

trials of ICS administered concomitantly with long-acting bronchodilators. The identification of surrogate markers of small airway inflammation evaluable in both smokers and ex-smokers would aid this process. Recent work suggests that alveolar nitric oxide (NO) is not a useful marker for monitoring response to COPD therapy. ${ }^{28}$

Our composite exacerbation definition included lower respiratory tract antibiotic therapy (or an oral corticosteroid course or unscheduled hospitalization or ED visit).
At least one antibiotic prescription for lower respiratory tract infection was prescribed during the 2 year follow-up for $47 \%$ of patients initiating extrafine beclomethasone and $40 \%$ initiating fluticasone, a statistically significant difference, which may need further study to assess whether this is a real observation. Of note, we found the opposite direction of effect in the step-up cohorts (although the difference was not statistically significant), as $49 \%$ and $56 \%$ of extrafine beclomethasone and fluticasone patients, respectively, 


\section{A}

Extrafine BDP $\square \mathrm{FP}$

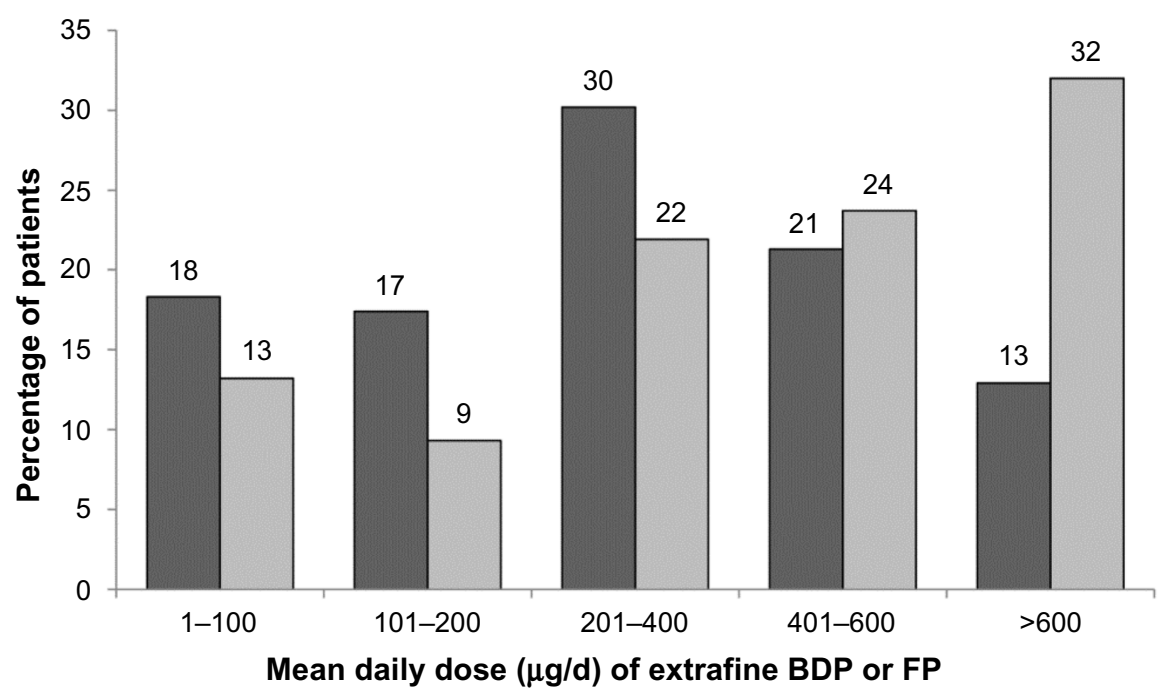

B

Extrafine BDP $\quad \square \mathrm{FP}$

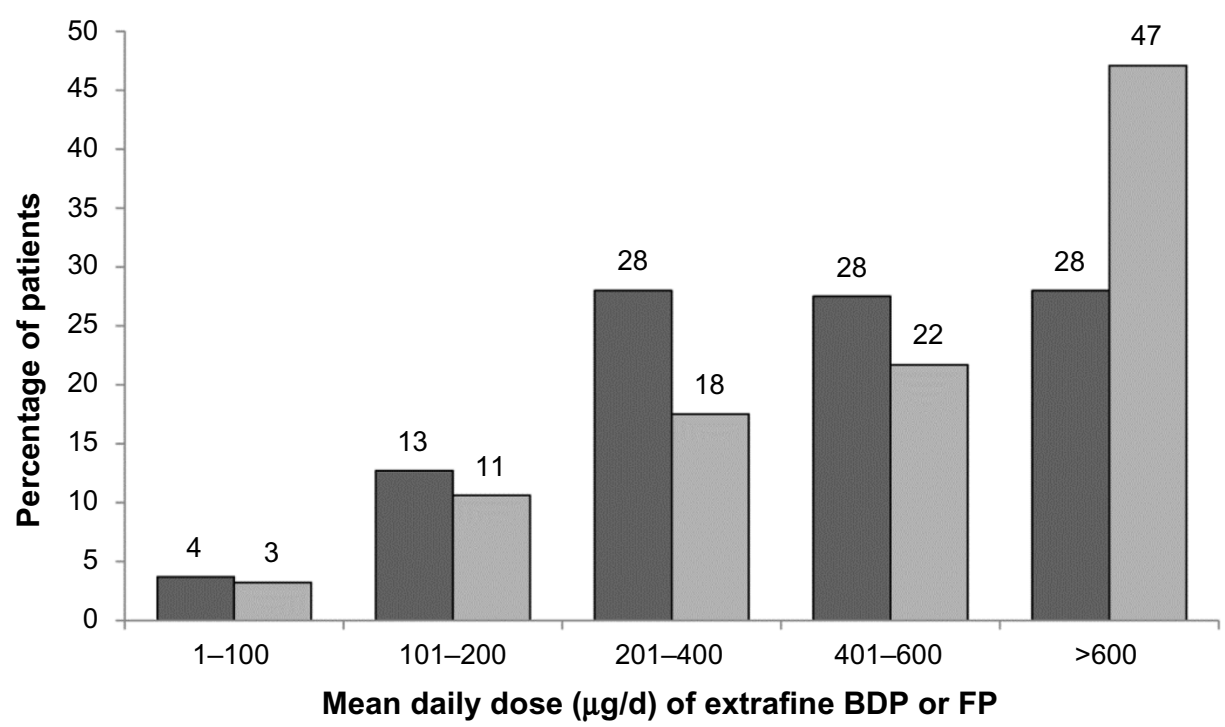

Figure 4 Mean daily ICS dose exposure for extrafine beclomethasone and fluticasone cohorts during the 2 year outcome period by $(\mathbf{A})$ the initiation sample and (B) the step-up sample.

Notes: $P<0.00$ I for the differences between cohorts. Percentages may not add up to $100 \%$ because of rounding. The mean daily dose exposure for each patient was calculated as the number of days' supply divided by 730 .

Abbreviations: BDP, beclomethasone dipropionate; FP, fluticasone propionate; ICS, inhaled corticosteroid.

received one or more antibiotic prescriptions. The fact of the results being in opposite directions could potentially be explained by the distribution of outliers during the baseline year, as patients with a higher number of baseline antibiotic prescriptions may be more likely to need antibiotic therapy during the outcome period: namely, in the initiation sample during baseline, 13 patients in the extrafine beclomethasone cohort versus five in the fluticasone cohort received from 4-8 courses of antibiotics; and in the step-up sample during baseline, three versus ten, respectively, received from 4-7 courses of antibiotics.

In addition to effectiveness of ICS it is important to assess side effects. ${ }^{1}$ Confirmed pneumonia was infrequent and comparable with both ICS treatments, recorded for three 
develops persistent airway obstruction over time, particularly when they smoke. ${ }^{31}$ We believe that the COPD diagnosis was valid for most patients under study for several reasons: 1) all patients had a recorded post-bronchodilator $\mathrm{FEV}_{1} / \mathrm{FVC}$ ratio of $<0.7$; 2) all were smokers or ex-smokers; 3 ) the mean age was 67 years, and the cohorts included a preponderance of men $(60 \%)$; 4 ) among those with an $\mathrm{FEV}_{1}$ reading at baseline ( $87 \%$ of the full population studied), the mean \%predicted $\mathrm{FEV}_{1}$ in the four cohorts ranged from $52 \%$ to $55 \%$ (depending on cohort); and from $60 \%$ to $69 \%$ of patients in each cohort had a $\%$ predicted $\mathrm{FEV}_{1}$ of $<60 \%$; 5) moreover, of the patients with an asthma codiagnosis, most also had substantial $\mathrm{FEV}_{1}$ impairment (mean $\mathrm{FEV}_{1}$ \%predicted, 53\%; data not shown); 6) finally, the COPD diagnosis was recorded at or close to the time of the asthma diagnosis for most patients, and, importantly, the COPD diagnosis was confirmed (via $\mathrm{FEV}_{1} /$ FVC ratio $<0.7$ ) for most patients after the asthma diagnosis was recorded (Figure S3). This suggests that the asthma codiagnosis was often an initial misdiagnosis that was later superseded by a diagnosis of COPD.

Retrospective studies such as this one are limited by the available data. All included patients had a database-recorded post-bronchodilator $\mathrm{FEV}_{1} / \mathrm{FVC}<0.7$; however, we were unable to track lung function during the outcome period because spirometry is not performed routinely in primary care. Moreover, not all potential matching criteria were available for all patients at baseline, including the $\mathrm{FEV}_{1}$ value (hence GOLD grade) and scores for the modified Medical Research Council or COPD Assessment Test, which would have enabled patient categorization according to recent GOLD guidelines. ${ }^{1}$ Nonetheless, patients appeared to be well-matched for physical characteristics and disease severity, and the analyses incorporated adjustments for residual confounding (although we cannot rule out unidentified confounding factors). Finally, the percentages of patients in each cohort who quit smoking during the outcome period would have been of interest, since the effects of ICS can be less in smokers with COPD.

\section{Conclusion}

This study has enabled us to describe the use of ICS for patients with COPD in UK primary care. We observed that ICS are prescribed, both as monotherapy and in combination with long-acting bronchodilators, for treating COPD and can result in improved exacerbation rates as in our COPD patients with predominantly GOLD grade 2 and 3 severity of airflow limitation. Our observations that small-particle ICS at significantly lower doses had the same effects as larger-particle ICS at higher doses and that small-particle ICS use was associated with greater odds of treatment stability and lower odds of treatment change during the 2 year' follow-up could be explained by greater lung deposition, especially to the small airways. Future pragmatic trials are needed to prospectively evaluate the effectiveness of ICS of differing particle sizes in COPD, administered concomitantly with long-acting bronchodilators.

\section{Acknowledgments}

We thank Professor Neil Barnes for his contributions in the early stages of the analyses, and we gratefully acknowledge Victoria Thomas for her assistance with the statistical analyses and production of figures.

\section{Author contributions}

$\mathrm{DP}$ and $\mathrm{AB}$ led the study design process; and all authors contributed to the design review. AB and $\mathrm{JvZ}$ are responsible for the data acquisition and analyses. EVH developed the first draft of the manuscript. All authors analyzed the data, developed drafts of the manuscript, and approved the final draft of the manuscript for submission. All the members of the steering committee and the additional experts who are responsible for this study are listed as authors of the study.

\section{Disclosure}

Data acquisition and the analyses were funded by Teva Pharmaceuticals; access to data from the Optimum Patient Care Research Database was co-funded by Research in Real Life Ltd (RiRL, Cambridge, UK). Teva played no role in the analysis or interpretation of the data, writing of the report, or decision to submit the paper for publication. The research team at RiRL designed the study, conducted the analyses, and coordinated the writing and revision of the paper in collaboration with the study steering committee, all of whom are named authors of the study.

In the past 3 years, The University of Groningen has received money for DSP regarding an unrestricted educational grant for research from AstraZeneca, Chiesi; travel to European Respiratory Society and/or American Thoracic Society meetings has been partially funded by AstraZeneca, Chiesi, GlaxoSmithKline (GSK), Nycomed; fees for consultancies were given to the University of Groningen by AstraZeneca, Boeringer Ingelheim, Chiesi, GSK, Nycomed, and Teva; travel and lectures in the People's Republic of China were paid by Chiesi.

NR received fees for speaking, organizing education and research or consulting from Aerocrine, Nycomed, AstraZeneca, Boehringer Ingelheim, Chiesi, GSK, Meda, 
Merck Sharp \& Dohme, Mundipharma, Novartis, Pfizer, Teva; and research funds from Boehringer Ingelheim, Pfizer, Novartis, Nycomed. GC is speaker/advisor/consultant for Teva, MedImmune, Alitair, Dey, Mylan, Novartis.

EI reports receiving consulting fees from Cowen \& Co, Infinity Pharmaceuticals, Merck, Regeneron Pharmaceuticals, Teva Specialty Pharmaceuticals; fees for expert testimony from Campbell, Campbell, Edwards and Conroy, Ficksman and Conley, Ryan Ryan Deluca LLP; lecturing fees from Merck; travel grant support from TEVA Specialty Pharmaceuticals, and having grant support paid to his institution from Amgen, i3 Research (Biota).

RJM has done consultancy work and/or received travel support and/or honoraria for attendance at advisory boards for Teva, AstraZeneca, MedImmune, and Merck; received research grants from MedImmune and the National Heart, Lung, and Blood Institute, and received royalties from UpToDate.

WMCvA is a member of medical advisory boards of Mundipharma BV, Astra-Zeneca, Teva, and received a travelling grant from Teva and a speaker's fee from Forest.

JG received honoraria from Novartis as a member of an advisory board for an asthma medication and received honoraria from GSK for advice on an asthma medication study design.

AB and JvZ are employees of RiRL.

$\mathrm{EVH}$ is a consultant for RiRL and has received payment for manuscript preparation from Merck, TevaFrance.

GG is an employee of Teva Pharmaceuticals.

DP has board membership with Aerocrine, Almirall, Amgen, AstraZeneca, Boehringer Ingelheim, Chiesi, Meda, Mundipharma, Napp, Novartis, and Teva; consultancy with Almirall, Amgen, AstraZeneca, Boehringer Ingelheim, Chiesi, GSK, Meda, Mundipharma, Napp, Novartis, Pfizer, and Teva; grants/grants pending with UK National Health Service, British Lung Foundation, Aerocrine, AstraZeneca, Boehringer Ingelheim, Chiesi, Eli Lilly, GSK, Meda, Merck, Mundipharma, Novartis, Orion, Pfizer, Respiratory Effectiveness Group, Takeda, Teva, and Zentiva; payments for lectures/speaking: Almirall, AstraZeneca, Boehringer Ingelheim, Chiesi, Cipla, GSK, Kyorin, Meda, Merck, Mundipharma, Novartis, Pfizer, SkyePharma, Takeda, and Teva; payment for manuscript preparation: Mundipharma and Teva; patents (planned, pending or issued): AKL Ltd; payment for the development of educational materials: GSK, Novartis; stock/stock options: shares in AKL Ltd which produces phytopharmaceuticals and owns $80 \%$ of Research in Real Life Ltd and its subsidiary social enterprise Optimum Patient Care; payment for travel/accommodations/meeting expenses from Aerocrine, Boehringer Ingelheim, Mundipharma, Napp, Novartis, and Teva; funding for patient enrollment or completion of research: Almirall, Chiesi, Teva, and Zentiva; peer reviewer for grant committees: Medical Research Council (2014), Efficacy and Mechanism Evaluation programme (2012), HTA (2014); unrestricted funding for investigatorinitiated studies: Aerocrine, AKL Ltd, Almirall, Boehringer Ingelheim, Chiesi, Meda, Mundipharma, Napp, Novartis, Orion, Takeda, Teva, Zentiva.

\section{References}

1. Global initiative for chronic Obstructive Lung Disease (GOLD) [homepage on the Internet]. Global Strategy for the Diagnosis, Management and Prevention of COPD [updated 2014]. Available from: http://www.goldcopd.org/. Accessed May 12, 2014.

2. Decramer M, Janssens W, Miravitlles M. Chronic obstructive pulmonary disease. Lancet. 2012;379(9823):1341-1351.

3. Hogg JC, Timens W. The pathology of chronic obstructive pulmonary disease. Annu Rev Pathol. 2009;4:435-459.

4. Hogg JC, Chu F, Utokaparch S, et al. The nature of small-airway obstruction in chronic obstructive pulmonary disease. $N$ Engl J Med. 2004;350(26):2645-2653.

5. McDonough JE, Yuan R, Suzuki M, et al. Small-airway obstruction and emphysema in chronic obstructive pulmonary disease. $N$ Engl $\mathrm{J}$ Med. 2011;365(17):1567-1575.

6. Galban CJ, Han MK, Boes JL, et al. Computed tomography-based biomarker provides unique signature for diagnosis of COPD phenotypes and disease progression. Nat Med. 2012;18(11):1711-1715.

7. Siddiqui S, Usmani OS. Small airways, big challenge: measuring the unseen? Nat Med. 2012;18(11):1619-1621.

8. Calverley PM, Anderson JA, Celli B, et al. Salmeterol and fluticasone propionate and survival in chronic obstructive pulmonary disease. N Engl J Med. 2007;356(8):775-789.

9. Singh S, Amin AV, Loke YK. Long-term use of inhaled corticosteroids and the risk of pneumonia in chronic obstructive pulmonary disease: a meta-analysis. Arch Intern Med. 2009;169(3):219-229.

10. Crim C, Calverley PM, Anderson JA, et al. Pneumonia risk in COPD patients receiving inhaled corticosteroids alone or in combination: TORCH study results. Eur Respir J. 2009;34(3):641-647.

11. Sharif R, Cuevas CR, Wang Y, Arora M, Sharma G. Guideline adherence in management of stable chronic obstructive pulmonary disease. Respir Med. 2013;107(7):1046-1052.

12. Ulrik CS, Hansen EF, Jensen MS, et al. Management of COPD in general practice in Denmark-participating in an educational program substantially improves adherence to guidelines. Int J Chron Obstruct Pulmon Dis. 2010;5:73-79.

13. Jebrak G, Initiatives BPCO. [COPD routine management in France: are guidelines used in clinical practice?]. Rev Mal Respir. 2010;27(1): 11-18. French.

14. Leach CL, Davidson PJ, Hasselquist BE, Boudreau RJ. Influence of particle size and patient dosing technique on lung deposition of HFA-beclomethasone from a metered dose inhaler. J Aerosol Med. 2005;18(4):379-385.

15. Leach CL, Davidson PJ, Hasselquist BE, Boudreau RJ. Lung deposition of hydrofluoroalkane-134a beclomethasone is greater than that of chlorofluorocarbon fluticasone and chlorofluorocarbon beclomethasone: a cross-over study in healthy volunteers. Chest. 2002;122(2):510-516.

16. Leach CL, Kuehl PJ, Chand R, Ketai L, Norenberg JP, McDonald JD. Characterization of respiratory deposition of fluticasone-salmeterol hydrofluoroalkane-134a and hydrofluoroalkane-134a beclomethasone in asthmatic patients. Ann Allergy Asthma Immunol. 2012;108(3):195-200. 
17. Clinical Practice Research Datalink [homepage on the Internet]. National Institute for Health Research. Available from: http://www. cprd.com/home/. Accessed May 12, 2014.

18. Optimum Patient Care Research Database (OPCRD) [homepage on the Internet]. Available from: http://www.optimumpatientcare.org/ Html_Docs/OPCRD.html. Accessed May 12, 2014.

19. Barnes N, Price D, Colice G, et al. Asthma control with extrafine-particle hydrofluoroalkane-beclometasone vs large-particle chlorofluorocarbonbeclometasone: a real-world observational study. Clin Exp Allergy. 2011;41(11):1521-1532.

20. Price D, Lee AJ, Sims EJ, et al. Characteristics of patients preferring once-daily controller therapy for asthma and COPD: a retrospective cohort study. Prim Care Respir J. 2013;22(2):161-168.

21. Wood L, Martinez C. The General Practice Research Database: role in pharmacovigilance. Drug Saf. 2004;27(12):871-881.

22. Global initiative for chronic Obstructive Lung Disease (GOLD) [homepage on the Internet]. Global strategy for the diagnosis, management, and prevention of chronic obstructive pulmonary disease, [updated 2007]. Available from: http://www.goldcopd.org/uploads/ users/files/GOLDReport07_0108.pdf. Accessed May 12, 2014.

23. Optimum Patient Care [homepage on the Internet]. Research in Real Life: Standard Operating Procedures. Optimum Patient Care. Available from: http://www.optimumpatientcare.org/Docs/SOP\%20Observational \%20Database\%20Studies.pdf. Accessed May 12, 2014.
24. Hurst JR, Vestbo J, Anzueto A, et al. Susceptibility to exacerbation in chronic obstructive pulmonary disease. N Engl J Med. 2010;363(12): 1128-1138.

25. Yang IA, Clarke MS, Sim EH, Fong KM. Inhaled corticosteroids for stable chronic obstructive pulmonary disease. Cochrane Database Syst Rev. 2012;7:CD002991.

26. Tzani P, Crisafulli E, Nicolini G, et al. Effects of beclomethasone/ formoterol fixed combination on lung hyperinflation and dyspnea in COPD patients. Int J Chron Obstruct Pulmon Dis. 2011;6:503-509.

27. Calverley PM, Kuna P, Monso E, et al. Beclomethasone/formoterol in the management of COPD: a randomised controlled trial. Respir Med. 2010;104(12):1858-1868.

28. Short PM, Williamson PA, Lipworth BJ. Effects of extra-fine inhaled and oral corticosteroids on alveolar nitric oxide in COPD. Lung. 2012;190(4):395-401.

29. Roche N, Reddel HK, Agusti A, et al. Integrating real-life studies in the global therapeutic research framework. Lancet Respir Med. 2013;1(10):e29-e30.

30. Price D, Bateman ED, Chisholm A, et al. Complementing the randomized controlled trial evidence base. Evolution not revolution. Ann Am Thorac Soc. 2014;11 Suppl 2:S92-S98.

31. Postma DS, Reddel HK, ten Hacken NH, van den Berge M. Asthma and chronic obstructive pulmonary disease: similarities and differences. Clin Chest Med. 2014;35(1):143-156. 


\section{Supplementary materials}

\section{Results for unmatched patient}

\section{populations}

- For the unmatched patients: prescribed inhaled corticosteroids doses were significantly lower for extrafine beclomethasone in both

- initiation sample: median interquartile range [IQR], 200 [200-400] versus fluticasone $500[500-1000] \mu \mathrm{g} / \mathrm{d}$; $P<0.001$, and

○ step-up sample: median [IQR], 400 [400-400] versus fluticasone $1,000[500-1,000] \mu \mathrm{g} / \mathrm{d} ; P<0.001$.

- For the unmatched patients: primary outcome measures showed no significant difference between cohorts in COPD exacerbation rate during outcome, with adjusted rate ratio

○ for initiation sample: 1.04 (95\% confidence interval [CI], 0.89-1.22) for extrafine beclomethasone relative to fluticasone

○ step-up sample: $0.94(95 \% \mathrm{CI}, 0.80-1.10)$ for extrafine beclomethasone.

- For the unmatched patients: there was no significant difference between cohorts in odds of COPD treatment success during outcome, with adjusted odds ratio

○ for initiation sample: 0.99 (95\% CI, 0.77-1.29) for extrafine beclomethasone relative to fluticasone

○ step-up sample: odds ratio 1.20 (95\% CI, 0.83-1.72) for extrafine beclomethasone.
Table SI Chronic respiratory diseases and database codes that were cause for study exclusion

\begin{tabular}{|c|c|}
\hline NHS read code & NHS read term \\
\hline AD5..00 & Sarcoidosis \\
\hline $\mathrm{H} 4 \ldots . .00$ & Lung disease due to external agents \\
\hline $\mathrm{H} 4 \ldots \mathrm{II}$ & Pneumoconiosis \\
\hline $\mathrm{H} 4 \ldots .12$ & Occupational lung disease \\
\hline $\mathrm{H} 40 . .00$ & Coal workers' pneumoconiosis \\
\hline $\mathrm{H} 4 \mathrm{I} . .00$ & Asbestosis \\
\hline $\mathrm{H} 4 \mathrm{I} 0.00$ & Pleural plaque disease/asbestosis \\
\hline $\mathrm{H} 4 \mathrm{lz} .00$ & Asbestosis NOS \\
\hline $\mathrm{H} 42 . .00$ & Silica/silicate pneumoconiosis \\
\hline $\mathrm{H} 420.00$ & Talc pneumoconiosis \\
\hline $\mathrm{H} 42 \mathrm{I} .00$ & Simple silicosis \\
\hline $\mathrm{H} 422.00$ & Complicated silicosis \\
\hline $\mathrm{H} 423.00$ & Massive silicotic fibrosis \\
\hline $\mathrm{H} 42 \mathrm{z} .00$ & Silica pneumoconiosis NOS \\
\hline $\mathrm{H} 43 . .00$ & Pneumoconiosis-other inorganic dust \\
\hline $\mathrm{H} 43 \mathrm{I} .00$ & Bauxite fibrosis of lung \\
\hline $\mathrm{H} 432.00$ & Berylliosis \\
\hline $\mathrm{H} 433.00$ & Graphite fibrosis of lung \\
\hline $\mathrm{H} 434.00$ & Siderosis \\
\hline $\mathrm{H} 435.00$ & Stannosis \\
\hline $\mathrm{H} 43 \mathrm{z} .00$ & Pneumoconiosis-inorganic dust NOS \\
\hline $\mathrm{H} 44 . .00$ & Pneumopathy-other dust inhalation \\
\hline $\mathrm{H} 440.00$ & Byssinosis \\
\hline $\mathrm{H} 44 \mathrm{I} .00$ & Cannabinosis \\
\hline $\mathrm{H} 44 \mathrm{z} .00$ & Pneumopathy-dust inhalation NOS \\
\hline $\mathrm{H} 45 . .00$ & Pneumoconiosis NOS \\
\hline $\mathrm{H} 450.00$ & Pneumoconiosis associated with tuberculosis \\
\hline $\mathrm{H} 46 . .00$ & Respiratory disease - chemical fumes \\
\hline $\mathrm{H} 460.00$ & Chemical bronchitis/pneumonitis \\
\hline $\mathrm{H} 460 \mathrm{z} 00$ & Chemical bronchitis/pneumonitis NOS \\
\hline $\mathrm{H} 464.00$ & Chronic chemical respiratory conditition \\
\hline $\mathrm{H} 464100$ & Chemical obliterative bronchiolitis \\
\hline $\mathrm{H} 464200$ & Chemical pulmonary fibrosis \\
\hline $\mathrm{H} 464 \mathrm{z} 00$ & Chronic chemical respiratory condition NOS \\
\hline $\mathrm{H} 46 \mathrm{z} .00$ & Chemical respiratory conditions NOS \\
\hline $\mathrm{H} 46 z z 00$ & Chemical respiratory conditions NOS \\
\hline $\mathrm{H} 48 . .00$ & Progressive massive fibrosis \\
\hline H4y..0O & External agent lung disease OS \\
\hline $\mathrm{H} 4 \mathrm{yl} .00$ & Chronic pulmonary radiation disease \\
\hline H4yl000 & Radiation pulmonary fibrosis \\
\hline $\mathrm{H} 4 \mathrm{ylz} 00$ & Chronic pulmonary radiation disease NOS \\
\hline $\mathrm{H} 4 \mathrm{y} 2.00$ & Drug-induced interstitial lung disorder \\
\hline $\mathrm{H} 4 \mathrm{y} 2100$ & Chronic drug-induced interstitial lung disorder \\
\hline H4yy.00 & Other external agent respiratory condition \\
\hline H4yz.00 & External agent respiratory condition NOS \\
\hline $\mathrm{H} 4 \mathrm{z} . .00$ & External agent lung disease NOS \\
\hline H57y200 & Pulmonary sarcoidosis \\
\hline
\end{tabular}

Abbreviations: NHS, National Health Service; NOS, not otherwise specified; OS, otherwise stated. 
Table S2 List of potential confounding variables considered for this study

- The index date

Potential confounders examined at (or closest to) the relevant index date

- Age

- Sex

- Height

- Weight

- Body mass index

- Lung function, in terms of spirometry before index date

- Smoking status

Potential confounders examined regardless of when they

occurred relative to the index date

- Date of first COPD diagnosis (where known)

- Other respiratory or other confounding diagnoses, including rhinitis, gastroesophageal reflux disease, and cardiac disease

Potential confounders examined in the year before

the index date

- Other important unrelated comorbidities expressed using the Charlson Comorbidity Index, calculated over the I year baseline period

- Number of general practice consultations for COPD or other respiratory illness

- Number of hospital outpatient attendances where COPD is recorded as the reason for referral

- Number of hospitalizations or emergency department attendance for COPD or possibly respiratory-related (a non-specific hospitalization code and a COPD/respiratory code within a I week window)

- Number of acute courses of oral corticosteroids

- Number of prescriptions for any antibiotic where the reason for the prescription is lower respiratory tract infection

- Other medications that might interfere with COPD control, including beta-blockers, NSAIDs, acetaminophen, and antidepressants

- Prior treatment classified as

$$
\begin{aligned}
& \text { - No drug therapy } \\
& \text { - SABA only } \\
& \text { - SAMA } \pm \text { SABA } \\
& \text { - LABA } \pm \text { SAMA } \pm \text { SABA } \\
& \text { - LAMA } \pm \text { SAMA } \pm \text { SABA } \\
& \text { - LAMA } \pm \text { LABA } \pm \text { SAMA } \pm \text { SABA }
\end{aligned}
$$

- Average ICS daily dose during baseline year

Abbreviations: COPD, chronic obstructive pulmonary disease; ICS, inhaled corticosteroid; LABA, long-acting $\beta_{2}$-agonist; LAMA, long-acting muscarinic antagonist; NSAID, nonsteroidal anti-inflammatory drug; SABA, short-acting $\beta_{2}$-agonist; SAMA, short-acting muscarinic antagonist. 
Table S3 Additional baseline patient characteristics by matched treatment cohort

\begin{tabular}{|c|c|c|c|c|c|c|}
\hline \multirow[t]{2}{*}{ Characteristic } & \multicolumn{3}{|c|}{ Initiation sample } & \multicolumn{3}{|l|}{ Step-up sample } \\
\hline & $\begin{array}{l}\text { Extrafine BDP } \\
(n=334)\end{array}$ & $\begin{array}{l}\text { Fluticasone } \\
(n=334)\end{array}$ & $P$-value ${ }^{a}$ & $\begin{array}{l}\text { Extrafine BDP } \\
(n=189)\end{array}$ & $\begin{array}{l}\text { Fluticasone } \\
(n=189)\end{array}$ & $P$-value ${ }^{a}$ \\
\hline \multicolumn{7}{|c|}{ Timing of COPD diagnosis code in database, $\mathrm{n}(\%)$} \\
\hline$>3 \mathrm{yr}$ before index date & $52(15.6)$ & $63(18.9)$ & 0.13 & $50(26.5)$ & $57(30.2)$ & 0.17 \\
\hline 6 mo to $3 \mathrm{yr}$ before index date & $82(24.6)$ & $81(24.3)$ & & $32(16.9)$ & $43(22.8)$ & \\
\hline At or $<6$ mo before index date & $102(30.5)$ & $117(35.0)$ & & $33(17.5)$ & $28(14.8)$ & \\
\hline$<3 \mathrm{yr}$ after index date & $66(19.8)$ & $40(12.0)$ & & $4 \mid(2 \mid .7)$ & $31(16.4)$ & \\
\hline$\geq 3 \mathrm{yr}$ after index date & $32(9.6)$ & $33(9.9)$ & & $33(17.5)$ & $30(15.9)$ & \\
\hline \multicolumn{7}{|l|}{ BMI category, n (\%) } \\
\hline Underweight (BMI $<18.5 \mathrm{~kg} / \mathrm{m}^{2}$ ) & $14(4.2)$ & $15(4.6)$ & 0.96 & $5(2.7)$ & $6(3.3)$ & 0.84 \\
\hline Normal (BMI I8.5-<24.5 kg/m²) & $132(39.9)$ & $125(38.1)$ & & $75(40.5)$ & $78(42.4)$ & \\
\hline Overweight (BMI $24.5-<30 \mathrm{~kg} / \mathrm{m}^{2}$ ) & $115(34.7)$ & I2I (36.9) & & $67(36.2)$ & $57(31.0)$ & \\
\hline Obese $\left(\mathrm{BMI} \geq 30 \mathrm{~kg} / \mathrm{m}^{2}\right)$ & $70(21.1)$ & $67(20.4)$ & & $38(20.5)$ & $43(23.4)$ & \\
\hline \multicolumn{7}{|c|}{$\geq$ I prescription in baseline year or at index date, $\mathrm{n}(\%)$} \\
\hline Beta blocker & $37(11.1)$ & $35(10.5)$ & 0.80 & $19(10.1)$ & $9(4.8)$ & 0.056 \\
\hline NSAID & $134(40.1)$ & $113(33.8)$ & 0.082 & $81(42.9)$ & $70(37.0)$ & 0.26 \\
\hline Paracetamol & II 4 (34.I) & $123(36.8)$ & 0.47 & $75(39.7)$ & $72(38.1)$ & 0.72 \\
\hline Antidepressant & $47(14.1)$ & $65(19.5)$ & 0.049 & $35(18.5)$ & $27(\mid 4.3)$ & 0.11 \\
\hline Daily SABA dose, median (IQR) & $219(110-548)$ & $219(110-548)$ & 0.77 & $384(219-658)$ & $438(219-767)$ & 0.22 \\
\hline Daily SAMA dose, median (IQR) & $0(0-55)$ & II (0-55) & 0.16 & $0(0-44)$ & $0(0-55)$ & 0.40 \\
\hline Pneumonia diagnosis, confirmed, n (\%) & $0(0)$ & $3(0.9)$ & $\mathrm{n} / \mathrm{a}$ & $\mathrm{I}(0.5)$ & $0(0)$ & $\mathrm{n} / \mathrm{a}$ \\
\hline
\end{tabular}

Notes: aMatched cohorts were compared using conditional logistic regression; ${ }^{b}$ recorded BMl data were available for 33 I (99\%) and 328 (98\%) patients in extrafine beclomethasone and fluticasone initiation cohorts, respectively, and for 185 (98\%) and 184 (97\%) patients in extrafine beclomethasone and fluticasone step-up cohorts, respectively.

Abbreviations: BDP, beclomethasone dipropionate; BMI, body mass index; COPD, chronic obstructive pulmonary disease; IQR, interquartile range; n/a, not applicable; NSAID, nonsteroidal anti-inflammatory drug; SABA, short-acting $\beta_{2}$-agonist; SAMA, short-acting muscarinic antagonist; yr, years; mo, months. 
Table S4 Baseline characteristics of unmatched cohorts

\begin{tabular}{|c|c|c|c|c|}
\hline \multirow[t]{2}{*}{ Characteristic } & \multicolumn{2}{|c|}{ Initiation - unmatched } & \multicolumn{2}{|c|}{ Step-up - unmatched } \\
\hline & $\begin{array}{l}\text { Extrafine BDP } \\
(n=938)\end{array}$ & $\begin{array}{l}\text { Fluticasone } \\
(n=443)\end{array}$ & $\begin{array}{l}\text { Extrafine BDP } \\
(n=372)\end{array}$ & $\begin{array}{l}\text { Fluticasone } \\
(n=606)\end{array}$ \\
\hline Male sex, n (\%) ${ }^{\mathrm{a}}$ & $535(57.0)$ & $259(58.5)$ & $206(55.4)$ & $325(53.6)$ \\
\hline Age at index date, mean (SD) ${ }^{a}$ & $67.5(9.5)$ & $65.6(8.8)$ & $67.8(10.1)$ & $65.2(9.5)$ \\
\hline $\mathrm{BMI}$ in kg/m², mean (SD) & $26.1(5.2)$ & $26.2(4.8)$ & $26.6(5.2)$ & $26.3(5.3)$ \\
\hline \multicolumn{5}{|l|}{ Charlson comorbidity index score, $n(\%)$} \\
\hline 0 & $577(6 \mid .5)$ & $268(60.5)$ & $236(63.4)$ & $360(59.4)$ \\
\hline I & $197(2 \mid)$ & $84(19)$ & $58(15.6)$ & $|2|(20.0)$ \\
\hline 2 & $96(10.2)$ & $58(13.1)$ & $50(13.4)$ & $70(11.6)$ \\
\hline$\geq 3$ & $68(7.2)$ & $33(7.4)$ & $28(7.5)$ & $55(9.1)$ \\
\hline Current smoker, n (\%) & $422(46.1)$ & $209(48.2)$ & I4I (39.1) & $267(45.9)$ \\
\hline Ex-smoker, n (\%) & $494(53.9)$ & $225(51.8)$ & $220(60.9)$ & $315(54.1)$ \\
\hline Index prescription date, mean (SD) ${ }^{a}$ & $2004.4(2.4)$ & $2002.3(2.6)$ & $2004.2(2.3)$ & $2001.3(2.8)$ \\
\hline \multicolumn{5}{|l|}{ Recorded comorbidity, n (\%) } \\
\hline Asthma diagnosis & $479(51.1)$ & $261(58.9)$ & $264(71.0)$ & $477(78.7)$ \\
\hline Rhinitis diagnosis & $116(12.4)$ & $66(14.9)$ & $47(12.6)$ & $98(16.2)$ \\
\hline GERD diagnosis & $145(15.5)$ & $70(15.8)$ & $47(12.6)$ & $|2|(20.0)$ \\
\hline Cardiac disease diagnosis & $186(19.8)$ & $58(13.1)$ & $74(19.9)$ & III (I8.3) \\
\hline \multicolumn{5}{|l|}{ Exacerbations, $\mathrm{n}(\%)^{\mathrm{b}}$} \\
\hline 0 (COPD treatment success) & $345(36.8)$ & $172(38.8)$ & $145(39.0)$ & $215(35.5)$ \\
\hline 1 & $251(26.8)$ & $113(25.5)$ & $93(25.0)$ & $137(22.6)$ \\
\hline$\geq 2$ & $342(36.5)$ & $158(35.7)$ & $134(36.0)$ & $254(41.9)$ \\
\hline Recorded \%predicted FEV , n (\%) & $835(89.0)$ & $374(84.4)$ & $34 \mid(9 \mid .7)$ & $517(85.3)$ \\
\hline \%predicted $\mathrm{FEV}_{1}$, mean (SD) & $55.3(18.5)$ & $52.0(18.9)$ & $56.3(19.9)$ & $49.5(18.7)$ \\
\hline \multicolumn{5}{|l|}{ GOLD grade (2008 criteria), n (\%) } \\
\hline GOLD I & $78(9.1)$ & $33(8.5)$ & $44(12.7)$ & $35(6.7)$ \\
\hline GOLD 2 & $431(50.1)$ & $161(41.6)$ & $168(48.4)$ & $198(37.6)$ \\
\hline GOLD 3 & $280(32.5)$ & $139(35.9)$ & $105(30.3)$ & $209(39.7)$ \\
\hline GOLD 4 & $72(8.4)$ & $54(14.0)$ & $30(8.6)$ & $84(16.0)$ \\
\hline \multicolumn{5}{|l|}{ Baseline therapy, n (\%) } \\
\hline SABA & $56(6.0)$ & $30(6.8)$ & I 48 (39.8) & $198(32.7)$ \\
\hline SAMA & $308(32.8)$ & $155(35.0)$ & $17(4.6)$ & $12(2.0)$ \\
\hline SAMA + SABA & $72(7.7)$ & $76(17.2)$ & $66(17.7)$ & $126(20.8)$ \\
\hline $\mathrm{LABA} \pm \mathrm{SAMA} \pm \mathrm{SABA}$ & $47(5.0)$ & $14(3.2)$ & $86(23.1)$ & $223(36.8)$ \\
\hline $\mathrm{LAMA} \pm \mathrm{SAMA} \pm \mathrm{SABA}$ & II (I.2) & $4(0.9)$ & $21(5.6)$ & $7(1.2)$ \\
\hline LAMA + LABA \pm SAMA $\pm S A B A$ & $15(1.6)$ & II (2.5) & $23(6.2)$ & $19(3.1)$ \\
\hline Other & $94(10.0)$ & $84(19.0)$ & II (3.0) & $21(3.5)$ \\
\hline LABA during baseline year, $\mathrm{n}(\%)$ & $6(3-10)$ & $5(3-11)$ & $110(29.6)$ & $247(40.8)$ \\
\hline COPD prescriptions, median (IQR) & $56(6.0)$ & $30(6.8)$ & $9(5-13)$ & $10(6-14)$ \\
\hline Mean daily ICS dose, $\mathrm{n}(\%)^{\mathrm{a}, \mathrm{b}}$ & $\mathrm{n} / \mathrm{a}$ & $\mathrm{n} / \mathrm{a}$ & & \\
\hline $\mathrm{I}-50 \mu \mathrm{g} / \mathrm{d}$ & $\mathrm{n} / \mathrm{a}$ & $\mathrm{n} / \mathrm{a}$ & $29(7.8)$ & $26(4.3)$ \\
\hline $51-100 \mu \mathrm{g} / \mathrm{d}$ & $\mathrm{n} / \mathrm{a}$ & $\mathrm{n} / \mathrm{a}$ & $82(22.0)$ & $89(14.7)$ \\
\hline $10 \mathrm{I}-200 \mu \mathrm{g} / \mathrm{d}$ & $\mathrm{n} / \mathrm{a}$ & $\mathrm{n} / \mathrm{a}$ & $115(30.9)$ & $170(28.1)$ \\
\hline $20 \mathrm{I}-400 \mu \mathrm{g} / \mathrm{d}$ & $\mathrm{n} / \mathrm{a}$ & $\mathrm{n} / \mathrm{a}$ & $106(28.5)$ & $156(25.7)$ \\
\hline$>400 \mu \mathrm{g} / \mathrm{d}$ & $\mathrm{n} / \mathrm{a}$ & $\mathrm{n} / \mathrm{a}$ & $40(10.8)$ & $165(27.2)$ \\
\hline Oral candidiasis, diagnosis/Rx, n (\%) & $16(1.7)$ & $12(2.7)$ & $18(4.8)$ & $38(6.3)$ \\
\hline $\begin{array}{l}\geq \mathrm{I} \text { Inpatient admission for COPD/lower } \\
\text { respiratory condition, } n(\%)\end{array}$ & $13(1.4)$ & $9(2.0)$ & $4(1.1)$ & II (I.8) \\
\hline Antibiotics: I prescription, n (\%) & $206(22.0)$ & $103(23.3)$ & $81(21.8)$ & $125(20.6)$ \\
\hline$\geq 2$ prescriptions, $\mathrm{n}(\%)$ & $155(16.5)$ & $49(11.1)$ & $51(13.7)$ & $99(16.3)$ \\
\hline Daily SABA dose, median (IQR) & $219(110-548)$ & $219(110-548)$ & $438(164-712)$ & $493(219-877)$ \\
\hline Daily SAMA dose, median (IQR) & $0(0-44)$ & II (0-55) & $0(0-44)$ & $0(0-66)$ \\
\hline Pneumonia diagnosis, confirmed, n (\%) & $5(0.5)$ & $3(0.7)$ & I $(0.3)$ & $3(0.5)$ \\
\hline
\end{tabular}

Notes: aMatching variable (age matching was \pm 5 years and index prescription date \pm 1 year for the initiation population and \pm 2 years for the step-up population); ${ }^{b}$ the doses of ICS were standardized to equivalence with extrafine beclomethasone and fluticasone; thus, baseline doses of large-particle beclomethasone and budesonide were halved. The daily dose was calculated as the number of days' supply divided by number of prescription days.

Abbreviations: BDP, beclomethasone dipropionate; BMI, body mass index; COPD, chronic obstructive pulmonary disease; diagnosis/Rx, coded diagnosis or therapy for same; FEV , forced expiratory volume in I second; GERD, gastroesophageal reflux disease; GOLD, Global initiative for chronic Obstructive Lung Disease; ICS, inhaled corticosteroid; IQR, interquartile range; $n / a$, not applicable; LABA, long-acting $\beta_{2}$-agonist; LAMA, long-acting muscarinic antagonist; NSAID, nonsteroidal anti-inflammatory drug; SABA, short-acting $\beta_{2}$-agonist; SAMA, short-acting muscarinic antagonist; SD, standard deviation. 
Table S5 Results during the 2 year outcome period for the initiation sample, unmatched cohorts, no treatment change

\begin{tabular}{|c|c|c|c|}
\hline Outcome & $\begin{array}{l}\text { Extrafine BDP } \\
(n=4 \mid 3)\end{array}$ & $\begin{array}{l}\text { Fluticasone } \\
(n=180)\end{array}$ & $\begin{array}{l}\text { Adjusted odds, hazard, or rate } \\
\text { ratio for extrafine BDP }(95 \% \mathrm{Cl})\end{array}$ \\
\hline \multicolumn{4}{|l|}{ Coprimary outcome measures } \\
\hline COPD treatment success ( 0 exacerbations) & $170(4 \mid .2)$ & $79(43.9)$ & OR $0.93(0.64-1.37)^{\mathrm{b}}$ \\
\hline Exacerbations over 2 years & & & RR $0.89(0.66-1.20)^{c}$ \\
\hline 0 & $170(4 \mid .2)$ & $79(43.9)$ & \\
\hline I & $98(23.7)$ & $40(22.2)$ & \\
\hline $2-3$ & $83(20.1)$ & $36(20.0)$ & \\
\hline 4-6 & $46(11.1)$ & $8(4.4)$ & \\
\hline$\geq 7$ & $16(3.9)$ & $17(9.4)$ & \\
\hline \multicolumn{4}{|l|}{ Secondary outcome measures } \\
\hline \multirow[t]{2}{*}{ Time to first exacerbation, median $(95 \% \mathrm{Cl})$, days } & & & HR I.05 $(0.82-1.34)^{d}$ \\
\hline & & & $P$-value ${ }^{a}$ \\
\hline \multicolumn{4}{|l|}{ Disaggregated outcome measures } \\
\hline I oral corticosteroid course & $53(12.8)$ & $22(12.2)$ & 0.75 \\
\hline$\geq 2$ oral corticosteroid courses & $42(10.2)$ & $15(8.3)$ & \\
\hline I lower respiratory infection + antibiotic $R x$ & $86(20.8)$ & $35(19.4)$ & 0.68 \\
\hline$\geq 2$ lower respiratory infections + antibiotic $R x$ & $76(18.4)$ & $29(16.1)$ & \\
\hline$\geq I$ hospitalization for COPD or lower respiratory & $3(0.7)$ & $\mathrm{I}(0.6)$ & 0.82 \\
\hline Daily ICS dose $(\mu \mathrm{g} / \mathrm{d})$, median (IQR) & $219(110-356)$ & $390(138-740)$ & $<0.001$ \\
\hline Daily SABA dose $(\mu \mathrm{g} / \mathrm{d})$, median (IQR) & $712(329-1,315)$ & $7 / 2(274-1,452)$ & 0.70 \\
\hline Increase in ICS dose by $\geq 50 \%$ & $43(10.4)$ & $18(10.0)$ & 0.88 \\
\hline Continuing LABA from baseline & $53(12.8)$ & $46(25.6)$ & \\
\hline Confirmed pneumonia diagnosis & $\mathrm{I}(0.2)$ & $\mathrm{I}(0.6)$ & Not applicable \\
\hline
\end{tabular}

Notes: Data are $\mathrm{n}(\%)$ unless otherwise indicated. ${ }^{\mathrm{C} C o n d i t i o n a l ~ l o g i s t i c ~ r e g r e s s i o n . ~ A d j u s t e d ~ f o r ~ b a s e l i n e: ~ b a d j u s t e d ~ f o r: ~ a g e, ~ a n t i b i o t i c s ~ u s e ~(w i t h ~ a ~ l o w e r ~ r e s p i r a t o r y ~ r e a d ~ c o d e ~}$ within a \pm 5 day window) (categorized), prescriptions for theophylline (Yes/No) and time between first coded diagnosis at practice and the index date (categorized); cadjusted for: age, rhinitis diagnosis (Yes/No), antibiotics use (with a lower respiratory read code within a \pm 5 day window) (categorized), acute use of oral steroids (categorized), number of lower respiratory-related consultations (categorized), beta blockers (Yes/No), prescriptions for theophylline (Yes/No) and Year of first coded diagnosis at practice (categorized); dadjusted for: age, antibiotics use (with a lower respiratory read code within a \pm 5 day window) (categorized), number of COPD consultations (categorized), prescriptions for theophylline (Yes/No) and inpatient admissions for COPD (Yes/No).

Abbreviations: $\mathrm{HR}$, hazard ratio; OR, odds ratio; RR, rate ratio; $\mathrm{BDP}$, beclomethasone dipropionate; $\mathrm{Cl}$, confidence interval; COPD, chronic obstructive pulmonary disease; ICS, inhaled corticosteroid; IQR, interquartile range; LABA, long-acting $\beta_{2}$-agonist; Rx, treatment; SABA, short-acting $\beta_{2}$-agonist. 
Table S6 Unadjusted and adjusted results during the 2 year outcome period for the step-up sample, unmatched cohorts, no treatment change

\begin{tabular}{|c|c|c|c|}
\hline Outcome & $\begin{array}{l}\text { Extrafine BDP } \\
(n=\mid 78)\end{array}$ & $\begin{array}{l}\text { Fluticasone } \\
(n=240)\end{array}$ & $\begin{array}{l}\text { Adjusted odds, hazard, or rate } \\
\text { ratio for extrafine BDP }(95 \% \mathrm{Cl})\end{array}$ \\
\hline \multicolumn{4}{|l|}{ Coprimary outcome measures } \\
\hline COPD treatment success ( 0 exacerbations) & $65(36.5)$ & $86(35.8)$ & OR $0.80(0.50-1.29)^{\mathrm{b}}$ \\
\hline Exacerbations over 2 years & & & RR $0.97(0.74-1.26)^{c}$ \\
\hline 0 & $65(36.5)$ & $86(35.8)$ & \\
\hline I & $43(24.2)$ & $37(15.4)$ & \\
\hline $2-3$ & $39(21.9)$ & $55(22.9)$ & \\
\hline $4-6$ & $19(10.7)$ & $37(15.4)$ & \\
\hline$\geq 7$ & $12(6.7)$ & $25(10.4)$ & \\
\hline \multicolumn{4}{|l|}{ Secondary outcome measures } \\
\hline \multirow[t]{2}{*}{ Time to first exacerbation, median $(95 \% \mathrm{Cl})$, days } & & & HR I.IO (0.85-I.42) ${ }^{\mathrm{d}}$ \\
\hline & & & $P$-value ${ }^{a}$ \\
\hline \multicolumn{4}{|l|}{ Disaggregated outcome measures } \\
\hline I oral corticosteroid course & $27(15.2)$ & $37(15.4)$ & 0.005 \\
\hline$\geq 2$ oral corticosteroid courses & $26(14.6)$ & $66(27.5)$ & \\
\hline I lower respiratory infection + antibiotic Rx & $48(27.0)$ & $46(19.2)$ & 0.091 \\
\hline$\geq 2$ lower respiratory infections + antibiotic $R x$ & $29(16.3)$ & $54(22.5)$ & \\
\hline$\geq$ I hospitalization for COPD or lower respiratory & $7(3.9)$ & $3(1.3)$ & 0.076 \\
\hline Daily ICS dose $(\mu \mathrm{g} / \mathrm{d})$, median (IQR) & $4 I I(219-575)$ & $740(432-1,027)$ & $<0.001$ \\
\hline Daily SABA dose $(\mu \mathrm{g} / \mathrm{d})$, median (IQR) & $822(329-1,315)$ & $\mathrm{I}, 096(438-1,78 \mid)$ & 0.002 \\
\hline Increase in ICS dose by $\geq 50 \%$ & $4(2.2)$ & $12(5.0)$ & 0.15 \\
\hline Continuing LABA from baseline & $61(34.3)$ & $|2|(50.4)$ & 0.001 \\
\hline Confirmed pneumonia diagnosis & $2(1.1)$ & $2(0.8)$ & 0.76 \\
\hline
\end{tabular}

Notes: Data are $\mathrm{n}(\%)$ unless otherwise indicated. ${ }^{\mathrm{a} C o n d i t i o n a l ~ l o g i s t i c ~ r e g r e s s i o n . ~ A d j u s t e d ~ f o r ~ b a s e l i n e: ~ b a d j u s t e d ~ f o r: ~ a s t h m a ~ d i a g n o s i s ~(Y e s / N o), ~ G E R D ~ d i a g n o s i s ~ a n d / o r ~}$ therapy (Yes/No), cardiac disease diagnosis and/or therapy (Yes/No), acute use of oral steroids (categorized), number of primary care consultations (categorized), prior LABA use (Yes/No) and time between first coded diagnosis at practice and the index date (categorized); cadjusted for: antibiotics use (with a lower respiratory read code within a \pm 5 day window) (categorized), acute use of oral steroids (categorized), number of COPD consultations (categorized), average daily ICS dose (categorized), prescriptions for paracetamol (Yes/No), prior LABA use (Yes/No) and time between first coded diagnosis at practice and IPD (categorized); dadjusted for: GERD diagnosis and/or therapy (Yes/No), antibiotics use (with a lower respiratory read code within a \pm 5 day window) (categorized 0-1/2+ to meet proportional hazards requirement), acute use of oral steroids (categorized 0-1/2+ to meet proportional hazards requirement), prior LABA use (Yes/No) and number of primary care consultations (categorized). Abbreviations: $\mathrm{HR}$, hazard ratio; $\mathrm{OR}$, odds ratio; $\mathrm{RR}$, rate ratio; $\mathrm{BDP}$, beclomethasone dipropionate; $\mathrm{Cl}$, confidence interval; $\mathrm{COPD}$, chronic obstructive pulmonary disease; GERD, gastroesophageal reflux disease; ICS, inhaled corticosteroid; IQR, interquartile range; LABA, long-acting $\beta_{2}$-agonist; Rx, treatment; SABA, short-acting $\beta_{2}$-agonist.

Table S7 Post-study mortality rates

\begin{tabular}{|c|c|c|c|c|}
\hline & \multicolumn{2}{|l|}{ Initiation sample } & \multicolumn{2}{|l|}{ Step-up sample } \\
\hline & $\begin{array}{l}\text { Extrafine BDP } \\
(n=334)\end{array}$ & $\begin{array}{l}\text { Fluticasone } \\
(n=334)\end{array}$ & $\begin{array}{l}\text { Extrafine BDP } \\
(n=\mid 89)\end{array}$ & $\begin{array}{l}\text { Fluticasone } \\
(n=189)\end{array}$ \\
\hline Follow-up time in years ${ }^{\mathrm{a}}$ mean (SD) & $6.6(2.5)$ & $7.0(2.6)$ & $6.4(2.3)$ & $7.2(2.3)$ \\
\hline Number of deaths, $n(\%)$ & $58(17.4)$ & $64(19.2)$ & $26(13.8)$ & $39(20.6)$ \\
\hline All-cause mortality, adjusted HR $(95 \% \mathrm{Cl})$ & $1.07(0.68-1.70)^{\mathrm{b}}$ & 1.00 & $1.23(0.6 \mathrm{I}-2.47)^{\mathrm{c}}$ & 1.00 \\
\hline
\end{tabular}

Notes: The study was not designed to evaluate mortality rates during treatment, as patients had to be alive throughout the 2 year outcome period to be eligible for the study. ${ }^{a}$ Follow-up time from index date until censored or the end of the study period (end of 20l0). Cox proportional hazards model: badjusted for Charlson comorbidity index score and smoking status; cadjusted for age and cardiac disease diagnosis or therapy.

Abbreviations: BDP, beclomethasone dipropionate; $\mathrm{Cl}$, confidence interval; $\mathrm{HR}$, hazard ratio; SD, standard deviation. 


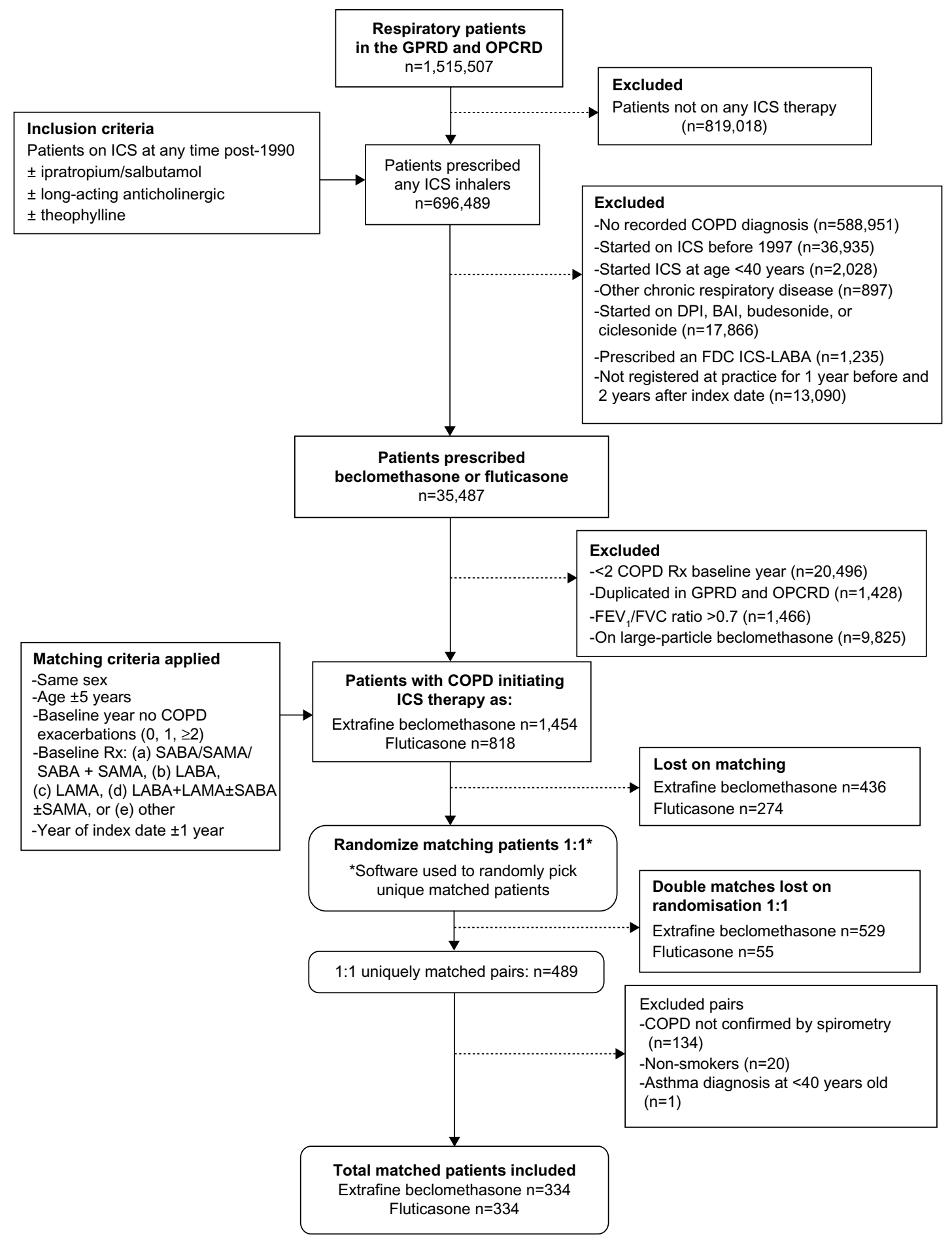

Figure SI Patient selection and matching for the initiation sample.

Note: Patients in the two treatment cohorts were matched on clinically and demographically significant characteristics.

Abbreviations: BAI, breath-actuated inhaler; COPD, chronic obstructive pulmonary disease; DPI, dry powder inhaler; FDC, fixed-dose combination; FEV , forced expiratory volume in I second; FVC, forced vital capacity; GPRD, General Practice Research Database; ICS, inhaled corticosteroid; LABA, long-acting $\beta_{2}$-agonist; LAMA, long-acting muscarinic antagonist; OPCRD, Optimum Patient Care Research Database; Rx, therapy; SABA, short-acting $\beta_{2}$-agonist; SAMA, short-acting muscarinic antagonist. 


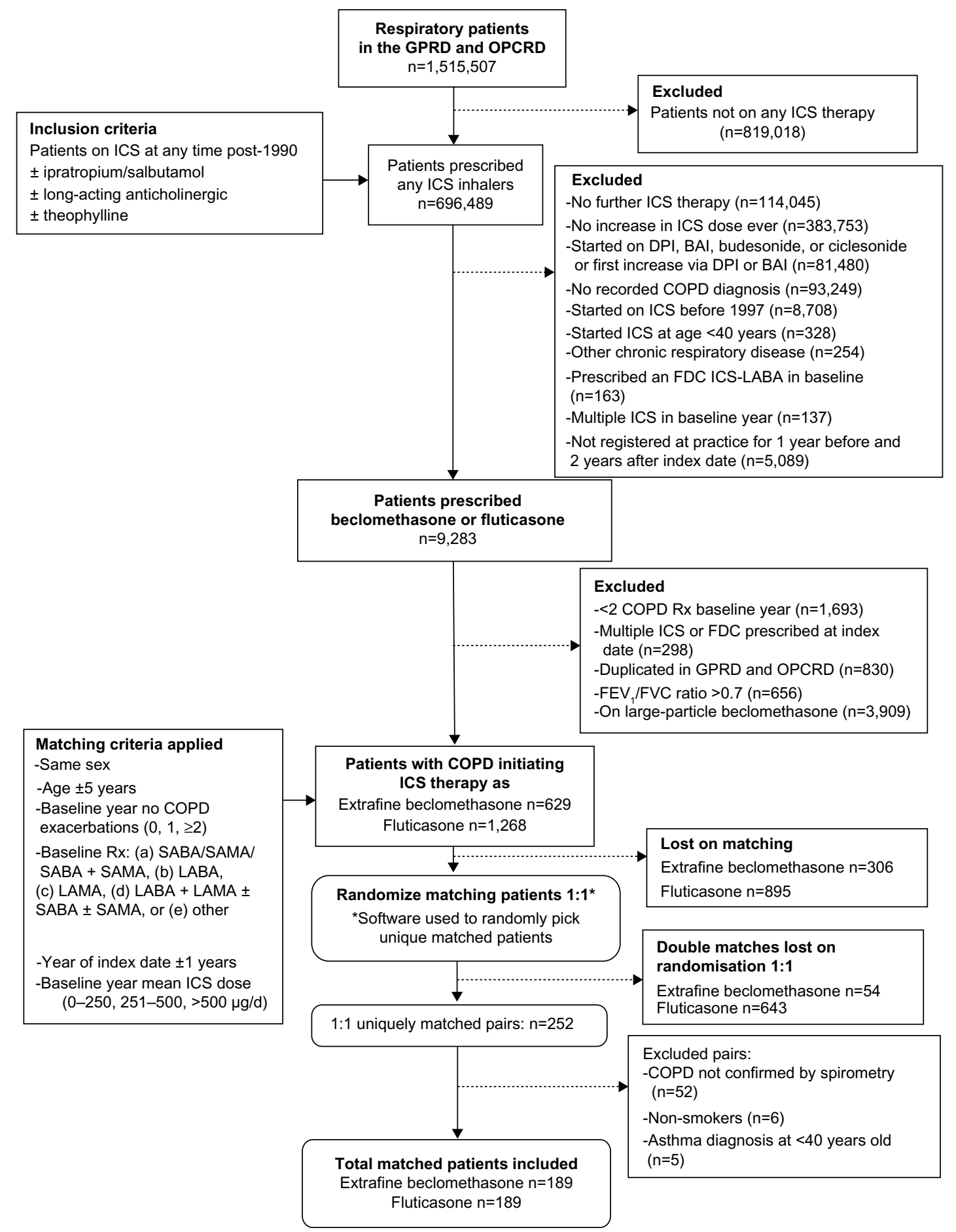

Figure S2 Patient selection and matching for the step-up sample.

Abbreviations: $\mathrm{BAI}$, breath-actuated inhaler; COPD, chronic obstructive pulmonary disease; DPI, dry powder inhaler; FDC, fixed-dose combination; FEV , forced expiratory volume in I second; FVC, forced vital capacity; GPRD, General Practice Research Database; ICS, inhaled corticosteroid; LABA, long-acting $\beta_{2}$-agonist; LAMA, long-acting muscarinic antagonist; OPCRD, Optimum Patient Care Research Database; Rx, therapy; SABA, short-acting $\beta_{2}$-agonist; SAMA, short-acting muscarinic antagonist. 

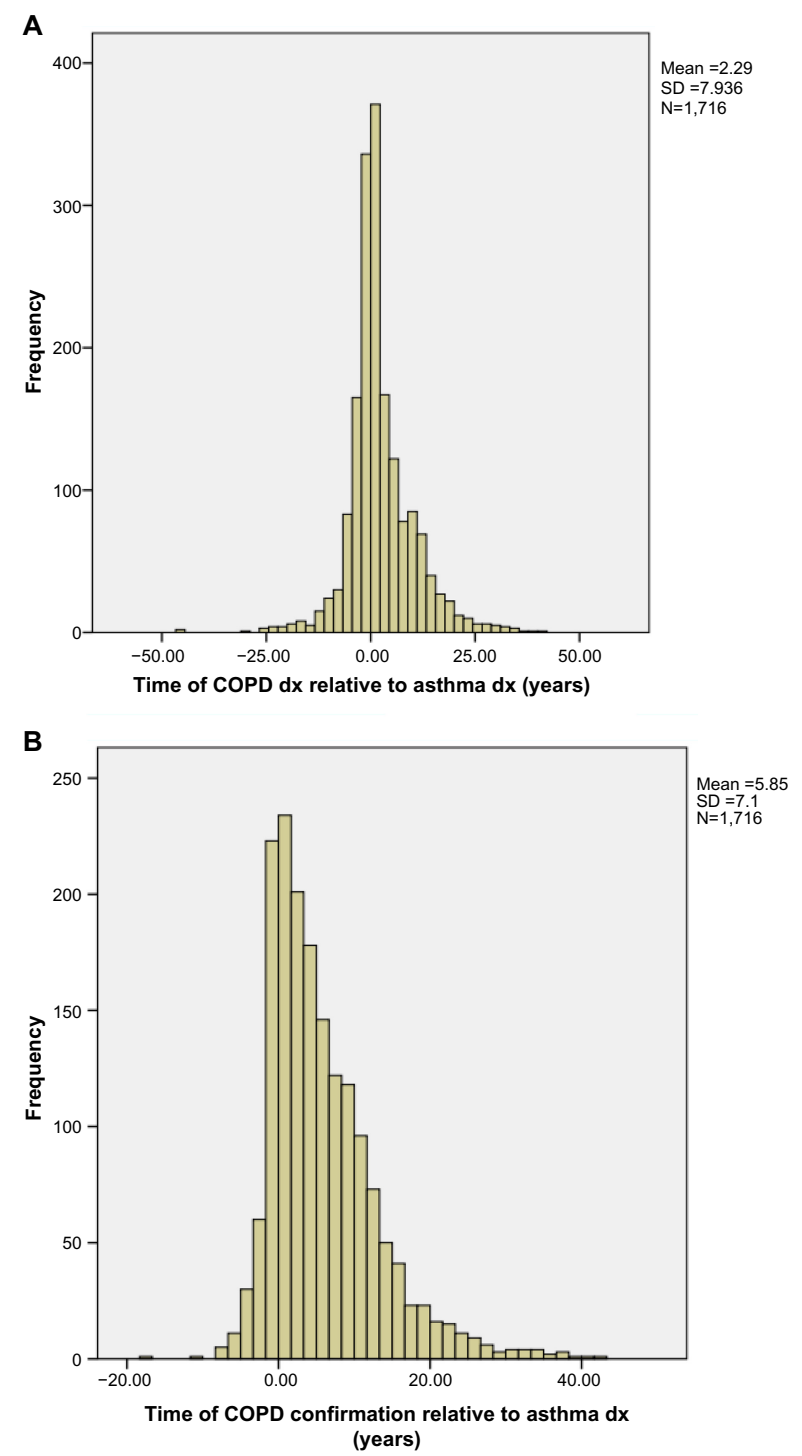

Figure S3 Time plots of the COPD diagnosis showing $(\mathbf{A})$ the time of the COPD diagnosis relative to time of first asthma diagnosis for the full unmatched population who also had a recorded asthma diagnosis, and (B) the time of the COPD confirmation (by $\mathrm{FEV}, / \mathrm{FVC}$ ratio $<0.7$ ) relative to time of the asthma diagnosis for these patients.

Abbreviations: COPD, chronic obstructive pulmonary disease; $\mathrm{dx}$, diagnosis; $\mathrm{SD}$, standard deviation; $\mathrm{FEV}_{1}$, forced expiratory volume in I second; FVC, forced vital capacity.

\section{Publish your work in this journal}

The International Journal of COPD is an international, peer-reviewed journal of therapeutics and pharmacology focusing on concise rapid reporting of clinical studies and reviews in COPD. Special focus is given to the pathophysiological processes underlying the disease, intervention programs, patient focused education, and self management protocols.

\section{Dovepress}

This journal is indexed on PubMed Central, MedLine and CAS. The manuscript management system is completely online and includes a very quick and fair peer-review system, which is all easy to use. Visit http://www.dovepress.com/testimonials.php to read real quotes from published authors. 